\title{
Degeneration of ipRGCs in Mouse Models of Huntington's Disease Disrupts Non-Image-Forming Behaviors Before Motor Impairment
}

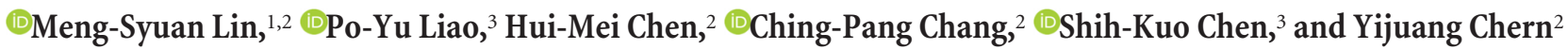 \\ ${ }^{1}$ Taiwan International Graduate Program in Molecular Medicine, National Yang-Ming University and Academia Sinica, Taipei 115, Taiwan, ${ }^{2}$ Institute of \\ Biomedical Sciences, Academia Sinica, Taipei 115, Taiwan, and ${ }^{3}$ Department of Life Science, National Taiwan University, Taipei 106, Taiwan
}

Intrinsically photosensitive retinal ganglion cells (ipRGCs), which express the photopigment melanopsin, are photosensitive neurons in the retina and are essential for non-image-forming functions, circadian photoentrainment, and pupillary light reflexes. Five subtypes of ipRGCs (M1-M5) have been identified in mice. Although ipRGCs are spared in several forms of inherited blindness, they are affected in Alzheimer's disease and aging, which are associated with impaired circadian rhythms. Huntington's disease (HD) is an autosomal neurodegenerative disease caused by the expansion of a CAG repeat in the huntingtin gene. In addition to motor function impairment, $\mathrm{HD}$ mice also show impaired circadian rhythms and loss of ipRGC. Here, we found that, in HD mouse models (R6/2 and N171-82Q male mice), the expression of melanopsin was reduced before the onset of motor deficits. The expression of retinal T-box brain 2, a transcription factor essential for ipRGCs, was associated with the survival of ipRGCs. The number of M1 ipRGCs in R6/2 male mice was reduced due to apoptosis, whereas non-M1 ipRGCs were relatively resilient to HD progression. Most importantly, the reduced innervations of M1 ipRGCs, which was assessed by X-gal staining in $\mathrm{R} 6 / 2-0 \mathrm{PN} 4^{\mathrm{Lacz} /+}$ male mice, contributed to the diminished light-induced c-fos and vasoactive intestinal peptide in the suprachiasmatic nuclei $(\mathrm{SCN})$, which may explain the impaired circadian photoentrainment in HD mice. Collectively, our results show that M1 ipRGCs were susceptible to the toxicity caused by mutant Huntingtin. The resultant impairment of M1 ipRGCs contributed to the early degeneration of the ipRGC-SCN pathway and disrupted circadian regulation during HD progression.

Key words: circadian disruption; ipRGC; melanopsin; SCN; Tbr2; VIP

Significance Statement

Circadian disruption is a common nonmotor symptom of Huntington's disease (HD). In addition to the molecular defects in the suprachiasmatic nuclei (SCN), the cause of circadian disruption in HD remains to be further explored. We hypothesized that ipRGCs, by integrating light input to the SCN, participate in the circadian regulation in HD mice. We report early reductions in melanopsin in two mouse models of HD, R6/2, and N171-82Q. Suppression of retinal T-box brain 2, a transcription factor essential for ipRGCs, by mutant Huntingtin might mediate the reduced number of ipRGCs. Importantly, M1 ipRGCs showed higher susceptibility than non-M1 ipRGCs in R6/2 mice. The resultant impairment of M1 ipRGCs contributed to the early degeneration of the ipRGC-SCN pathway and the circadian abnormality during HD progression.

\section{Introduction}

Huntington's disease (HD) is an inherited neurodegenerative disorder caused by abnormal accumulation of mutant Hunting- tin (HTT) proteins that express an expanded polyglutamine tract in their $\mathrm{N}$ termini. The primary symptom of motor incoordination in HD patients is due to neural loss and neuron excitotoxic- 
ity accelerated by mutant HTT protein expression in the striatum and cerebral cortex (Vonsattel and DiFiglia, 1998). In addition to severe motor dysfunction, nonmotor symptoms (such as cognitive functions, sleep, and circadian rhythms) are often impaired in HD patients. The symptomatic deterioration of these symptoms gradually affects the life quality of HD patients and their guardians (Morton, 2013). However, the mechanisms leading to the onset of nonmotor symptoms are poorly understood.

Previously, the disruption of circadian rhythms in several mouse models of HD has been documented (Morton et al., 2005; Kudo et al., 2011; Loh et al., 2013). The molecular oscillation in the suprachiasmatic nuclei (SCN), the central circadian clock, is first considered to be involved in circadian disturbances in HD. The amplitudes of prokineticin 2 and Bmall oscillations are weakened in the SCN at the manifest stage of a HD mouse model (R6/2) (Morton et al., 2005). The clock gene Period2 (Per2) is rhythmically expressed at lower levels in SCN in R6/2 mice, whereas it is normally expressed in another HD mouse model (BACHD). Compared with Per2, the rhythm of Period1 (Per1) is not affected in the SCN of R6/2 mice (Morton et al., 2005; Pallier et al., 2007; Kudo et al., 2011). However, the altered molecular oscillation does not completely explain the changes of circadian behavior in HD. Importantly, the SCN can be entrained to external environmental cues, such as light/dark (LD) cycles, by a specific type of retinal ganglion cells called intrinsically photosensitive retinal ganglion cells (ipRGCs). Due to the expression of the photopigment melanopsin, ipRGCs can respond to direct circadian photoentrainment and pupillary light reflexes (Berson et al., 2002; Lucas et al., 2003), serving as a relay station to integrate the rod/cone signals and intrinsic melanopsin-derived signals to drive non-image-forming functions (Güler et al., 2008). In the present study, we set out to investigate the contribution of the ipRGC-SCN pathway to the abnormal circadian rhythms in HD.

Five subtypes of ipRGCs (M1-M5) have been identified in mice, with different expression levels of melanopsin, dendritic stratification, and intrinsic electrophysiological properties (Berson et al., 2010; Hu et al., 2013). M1-ipRGCs, with their dendrites stratified exclusively at the OFF sublamina of the inner plexiform layer, primarily innervate the SCN for circadian photoentrainment, the shell of the olivary pretectal nucleus (OPN) for pupil constriction and the ventrolateral preoptic area for sleep regulation (Berson et al., 2002; Hattar et al., 2002). In contrast, non-M1 ipRGCs, with their dendrites stratified primarily at the ON sublamina of the inner plexiform layer, project to the core of the OPN, dorsal lateral geniculate nucleus (dLGN), and other brain regions that appear to control both non-image-forming and image-forming vision (Hattar et al., 2006; Ecker et al., 2010). Previously, the susceptibilities of ipRGCs have been reported in Alzheimer's disease (AD) (La Morgia et al., 2016) and HD (Ouk et al., 2016). However, the degenerated ipRGC subtypes and the underlying mechanisms remain elusive.

In the present study, we show that the melanopsin transcript and protein levels were reduced before the onset of motor impairment in HD mice (R6/2). Consistent with the loss of ipRGCs, 8 of 13 genes critical for ipRGCs were abnormally regulated during HD progression. In particular, the reduction of T-box brain 2, a transcription factor indispensable for ipRGC formation, was associated with the degeneration of ipRGCs. In addition, M1 was the most susceptible ipRGC subtype in HD mice to the toxicity caused by mutant HTT. The reduced number of M1 ipRGCs, together with the decreased M1 projections to SCN, support a role of declined ipRGC/SCN axis in circadian disruption. More- over, reduced M1 innervations to OPN and weakened synaptic connections may also affect pupillary light reflexes. Our findings suggest that the approaches to prevent ipRGC degeneration might ameliorate circadian disruption in HD and possibly other neurodegenerative diseases as well.

\section{Materials and Methods}

Animal models. Transgenic R6/2 mice (B6CBA-Tg(HDexon1)62Gpb/3J, IMSR catalog \#JAX:006494, RRID:IMSR_JAX:006494) and N171-82Q mice (B6C3-Tg(HD82Gln)81Gschi/J, IMSR catalog \#JAX:003627, RRID:IMSR_JAX:003627) (Schilling et al., 1999) were obtained from the The Jackson Laboratory. The R6/2 mice were maintained in a C57BL/6 and CBA/CaJ mixed background. The expansion of CAG repeats in R6/2 mice for the present studies was $187 \pm 1$ (mean \pm SEM). The N171-82Q mice were maintained on a C57BL/6 background for retinal analysis. The N171-82Q offspring containing Pde6b mutation were excluded by PCR analysis of genomic DNA extracted from mouse tails using the primers 5'-AAGCTAGCTGCAGTAACGCCATTT-3'， 5'-ACCTGCATGTGAA CCCAGTATTCTATC- $3^{\prime}$ and $5^{\prime}$-CTACAGCCCCTCTCCAAGGTTT ATAG-3' located in the Pde6b allele, and only the offspring without $P d e 6 b$ mutations were used in this study. R6/2-OPN4 ${ }^{\mathrm{Laz} /+}$ mice were generated by breeding R6/2 male mice and OPN $4^{\text {Lacz/Lacz }}$ female mice (Hattar et al., 2002). The knock-in Hdh ${ }^{(\mathrm{CAG}) 150 \mathrm{Q}}$ mice (B6.129P2Hdhtm2Detl/J) were initially obtained from The Jackson Laboratory (Lin et al., 2001). Homozygous Hdh ${ }^{\text {(CAG) } 150 Q}$ mice were assessed in this study. Mice were carefully bred at the Institute of Biomedical Sciences Animal Care Facility (Taipei, Taiwan) under a 12/12 h LD cycle and only male mice were assessed in this study. Animal experimental protocols performed in this study were approved by the Academia Sinica Institutional Animal Care and Utilization Committee (Taipei, Taiwan).

Immunohistochemical analysis. Mice were anesthetized via intraperitoneal injection of pentobarbital $(80 \mathrm{mg} / \mathrm{kg})$ and underwent a fixation procedure with $4 \%$ paraformaldehyde in $0.1 \mathrm{~m}$ phosphate buffer, $\mathrm{pH}$ 7.4. After enucleating eyeballs and removing attached choroid and lens, whole-mount retinas were isolated and flattened by 4-relieved cuts. Brains were collected, cryoprotected in $30 \%$ sucrose in $0.1 \mathrm{M}$ phosphate buffer, pH 7.4, and coronally sectioned with a HM 430 Sliding Microtome (Thermo Fisher Scientific) to generate brain slices of $20-25 \mu \mathrm{m}$ thicknesses. For immunohistochemical analysis, after 3 washes with $0.1 \mathrm{M}$ PBS, retinas were transferred to blocking solution containing PBS with $0.3 \%$ Triton X-100 containing 5\% BSA or 3\% normal goat serum (NGS) for $3 \mathrm{~h}$ at room temperature and incubated in the desired concentration of primary antibodies prepared in blocking solution for $3-4 \mathrm{~d}$ at $4^{\circ} \mathrm{C}$. Primary antibodies used in the present study included anti-melanopsin (1:3000; Advanced Targeting Systems catalog \#UF006, RRID: AB_2314781), anti-Tbr2 (1:1000; Millipore catalog \#AB15894, RRID: AB_10615604), anti-Brn3a (1:200; Santa Cruz Biotechnology catalog \#sc-31984, RRID:AB_2167511), anti-RBPMS (1:2000; Millipore catalog \#ABN1376, RRID:AB_2687403), anti-c-Fos (1:2000; Santa Cruz Biotechnology catalog \#sc-271243, RRID:AB_10610067), anti-Smi-32 (1: 1000; Millipore catalog \#NE1023-100UL, RRID:AB_2043449), antivasoactive intestinal peptide (VIP) (1:1000, ImmunoStar catalog \#20077, RRID:AB_572270), and anti-arginine vasopressin (AVP) (1:1000; Millipore catalog \#AB1565, RRID:AB_90782). After washing with PBS, retinas were further incubated with the desired fluorescently labeled secondary antibody conjugates for $1 \sim 2 \mathrm{~h}$ at room temperature and nuclei were labeled by Hoechst 33258 staining. Retinas or brain slides were mounted with mounting media (Vector Laboratories).

For c-fos immunostaining, mice were first entrained to $12 / 12 \mathrm{~h} \mathrm{LD}$ cycles for $10 \mathrm{~d}$. The mice at the indicated age were exposed to a $15 \mathrm{~min}$ light pulse (500 lux, fluorescent light) at ZT16 and then returned to a dark phase for 30 min before being killed; another group of mice was maintained in the dark phase at ZT16 as a control group. After $4 \%$ paraformaldehyde fixation, $4-6$ pieces of the coronal brain sections (20 $\mu \mathrm{m}$ ) containing SCN (bregma $-0.40 \sim-0.6 \mathrm{~mm}$ ) of the indicated mice were collected for $\mathrm{c}$-fos staining and quantification. Confocal image analysis was performed with an inverted confocal plus super-resolution Zeiss 
Table 1. Primer list for qRT-PCR

\begin{tabular}{|c|c|}
\hline Gene name & Primer sequence $5^{\prime} \rightarrow 3^{\prime}$ \\
\hline \multirow[t]{2}{*}{ Opn4 } & $5^{\prime}$-TAC CCT AGG CAC GGT GAT C-3' \\
\hline & 5'-GCT GAC TGC GAG GTT GAT GA-3' \\
\hline \multirow[t]{2}{*}{ Rbms3 } & $5^{\prime}$-AGC CGC ACA GAA AGC AGT-3' \\
\hline & $5^{\prime}$-GGA GAT GGG AAG GTT TGA-3' \\
\hline \multirow[t]{2}{*}{ Adcyap1 } & $5^{\prime}$-AGA CCA GAA GAC GAG GCT-3' \\
\hline & $5^{\prime}$-TCC GCT GGA TAG TAA AGG-3' \\
\hline \multirow[t]{2}{*}{ Gna14 } & 5'-CAT GGG TCT GGC TAC AGT-3' \\
\hline & 5'-TGG GCA TTT TCC TTA TTC-3' \\
\hline \multirow[t]{2}{*}{ Eomes } & $5^{\prime}$-GGG TCT TGT GGA GGA TTG G-3' \\
\hline & 5'-TGC CCT GTT TGG TGA TGA T-3' \\
\hline \multirow[t]{2}{*}{ lgf1 } & $5^{\prime}$-CTG CTT GCT CAC CTT CAC C-3' \\
\hline & 5'-ATA GCC TGT GGG CTT GTT G-3' \\
\hline \multirow[t]{2}{*}{ Gal } & 5'-ACT CTG GGA CTT GGG ATG-3' \\
\hline & 5'-TGC TTG TCG CTA AAT GAT-3' \\
\hline \multirow[t]{2}{*}{ Ctxn3 } & $5^{\prime}$-CAG GAG ATG AAT CAA GCG TT-3' \\
\hline & $5^{\prime}$-CAG GGA ATC CAG AGC ACA-3' \\
\hline \multirow[t]{2}{*}{ Prph } & 5'-ATG TGC GAG GTG GAT GGG-3' \\
\hline & 5'-TGC TGC GCC TGC TTG GTA-3' \\
\hline \multirow[t]{2}{*}{ Prkcq } & $5^{\prime}$-CAG AAA CAA CCG TGG AAC-3' \\
\hline & 5'-TGC ATT CAT TAG CAT TCG-3' \\
\hline \multirow[t]{2}{*}{ Msc } & 5'-AGG ACC GCT ACG AGG ACA-3' \\
\hline & 5'-AAG CGG AAG TTC CAC AAA-3' \\
\hline \multirow[t]{2}{*}{ Cd24a } & 5'-ATC TCC ACT TAC CGA ACA-3' \\
\hline & $5^{\prime}$-GGT AGG AGC AGT GCC AGA-3' \\
\hline \multirow[t]{2}{*}{ Kitl } & 5'-ACT CGC ACG GGC ACA TAC A-3' \\
\hline & $5^{\prime}$-ACA AGG GAA GGC CAA CCA G-3' \\
\hline \multirow[t]{2}{*}{ Stk32a } & $5^{\prime}$-GCG GAA TGA AGT GAG GAA-3' \\
\hline & $5^{\prime}-G C A$ GGT CAC CAC CGA GTA-3' \\
\hline \multirow[t]{2}{*}{ Trpc3 } & 5'-TAT TGG CTA TGT TCT TTA TG-3' \\
\hline & $5^{\prime}$-ACG AGC AAA CTT CCA TTC TA-3' \\
\hline \multirow[t]{2}{*}{ Trpc6 } & $5^{\prime}$-СTC CTC CCT AAT GAA ACC AG-3' \\
\hline & 5'-TTT CTT TAC ATT CAG CCC AT-3' \\
\hline \multirow[t]{2}{*}{ Trpc7 } & 5'-TAT TGG CTA TGT TCT TTA TG-3' \\
\hline & 5'-ACG AGC AAA CTT CCA TTC TA-3' \\
\hline \multirow[t]{2}{*}{ Beta-actin } & 5'-TTC TTT GCA GCT CCT TCG T-3' \\
\hline & $5^{\prime}$-GAT GGA GGG GAA TAC AGC C-3' \\
\hline
\end{tabular}

LSM 780 plus ELYRA microscope. The quantification of all images was processed by ImageJ (RRID:SCR_003070).

$X$-gal staining. X-gal staining was performed as described previously (Mombaerts et al., 1996). In R6/2-OPN4 $4^{\mathrm{Lacz} /+}$ mice or OPN $4^{\mathrm{Lacz} /+}$ mice, the fixation was performed as described previously and brain sections of $25 \mu \mathrm{m}$ thicknesses collected for X-gal staining. After washing in $0.1 \mathrm{M}$ phosphate buffer, $\mathrm{pH}$ 7.4, whole-mount retinas and the desired brain sections were incubated in X-gal staining solution at room temperature for $5 \mathrm{~d}$ in the dark. The formulation of the X-gal staining solution is as follows: $1 \mathrm{mg} / \mathrm{ml} \mathrm{X-gal} \mathrm{(5-bromo-4-chloro-3-indolyl-} \beta$-Dgalactopyranoside) in $0.1 \mathrm{M}$ phosphate buffer, $\mathrm{pH} 7.4$, containing potassium ferricyanide (5 $\mathrm{mm})$, potassium ferrocyanide (5 $\mathrm{mm}), \mathrm{MgCl}_{2}$ (2 $\mathrm{mm}$ ), and $0.02 \%$ Triton X-100. The X-gal-stained samples were mounted with $50 \%$ glycerol onto glass slides and imaged with an Axio Imager Z1 (Zeiss).

$R N A$ extraction and $q R T-P C R$. Total RNA of retinas in the indicated mice was extracted using GENEZOL TriRNA Pure kit (Geneaid) or TRIzol (Thermo Fisher Scientific) with treatment of RNase-free DNase (RQ1; Promega) to prevent genomic DNA contamination. Then, $1-2 \mu \mathrm{g}$ of extracted RNA was transcribed into cDNA using Superscript_III reverse transcriptase (Thermo Fisher Scientific). The levels of genes of interest (Table 1) in 2-5 ng of cDNA for each reaction were measured using Powerup SYBR Green Master Mixes (Thermo Fisher Scientific) and the primer mixture in a 7900HT Fast Real-Time PCR System (Applied Biosystems). The primer sequences are listed in Table 1 . The relative transcript level of the target gene was normalized to that of $\beta$-actin.

In situ RNA hybridization. In situ RNA hybridization was conducted by using RNAscope technology and RNA probes specific for mouse
Eomes and OPN4 (Advanced Cell Diagnostics). Briefly, retina were cryostat sectioned at $12 \mu \mathrm{m}$ by a Cryosectioning System (CM 3050S; Leica Biosystems) and mounted on SuperFrost Plus glass slides. Retina sections were pretreated with the boiled RNAscope target retrieval solution for 8-10 min, followed by incubation with the RNAscope protease IV at $40^{\circ} \mathrm{C}$ for $30 \mathrm{~min}$. After proper $\mathrm{ddH}_{2} \mathrm{O}$ washing, retina sections were hybridized with RNA probes at $40^{\circ} \mathrm{C}$ for $2 \mathrm{~h}$. The signal amplification steps followed the manufacturer's protocol and the fluorescence signal was visualized by an inverted confocal Zeiss LSM 780 plus ELYRA microscope. The sums of the fluorescence intensities of the RNA particles in single ipRGCs were measured by ImageJ software and are presented as mRNA expression per ipRGC.

Rotarod performance test. A rotarod device (Ugo Basile) was used to assess motor coordination of mice at a constant speed (12 rpm) over a period of $2 \mathrm{~min}$, as described previously (Carter et al., 1999). Pretraining to run on the rotarod device was required for all mice at the age of 5 weeks. The rotarod behaviors of each mouse were measured 3 times per week from the age of 6-12 weeks. For each test, mice were placed on the standing roller before the initiation of rolling and the latency to fall was recorded and analyzed.

Pupillary light reflex. Pupillary light reflexes were assessed as described previously (Chen et al., 2011). In brief, pupillary light reflexes were measured in mice at 2 light intensities ( 5 and 500 lux) in a dark environment. Mice were dark adapted for $1 \mathrm{~h}$ and a night vision camera with infrared red light was used to record the pupil constriction in the right eye at ZT4-5. After each mouse was restrained in an experimenter's hand, darkadapted pupil area was recorded for $10 \mathrm{~s}$. Light stimulation from a cold light source (Leica CLS $150 \mathrm{X}$ ) was provided to the left eye of mouse and the change in the pupil area was continuously recorded for $30 \mathrm{~s}$. Mice were exposed to low-light stimulation before high-light stimulation after an interval of $30 \mathrm{~min}$. Data were presented as the value of pupil area in light normalized to dark-adapted pupil area from each mouse. Pupillary light reflexes were longitudinally monitored in mice at the ages of 5, 7, and 10.5 weeks.

Wheel-running activity. Wheel-running experiments was performed and analyzed as described previously (Güler et al., 2008). Mouse wheelrunning cages (Coulbourn Instruments) were used to measure the wheel-running activity of mice. The activity units in actograms were presented at $5 \mathrm{~min}$. In the jet lag experiment, mice were first housed under 12/12 h LD cycle for $10 \mathrm{~d}$, followed by a $4 \mathrm{~h}$ advanced $(11 \mathrm{~d})$ and a $4 \mathrm{~h}$ delayed $(9 \mathrm{~d})$ phase shifting of LD cycles. The days for resynchronization, the amplitude of activities, the activities in darkness and lightness, tau, and acrophase were analyzed by Clocklab software (Coulbourn Instruments); 300-400 lux of fluorescent white light was used during the light phase.

In the light-masking experiment, the masking response to light in running activities was performed as described previously (Mrosovsky and Hattar, 2003). Mice in LD cycles were given by a $3 \mathrm{~h}$ light exposure at ZT14 at the age of 7 weeks; 800 lux of white light was used during the light phase. The running activities for $5 \mathrm{~d}$ before the experimental day were averaged as running activities in the darkness; the running activities in the $3 \mathrm{~h}$ light phase were presented as the masking response.

In the light-induced phase shift experiment, mice housed in a LD cycle for $9 \mathrm{~d}$ were exposed to a $15 \mathrm{~min}, 800$ lux light exposure at CT16 on day 11 and were then held in constant darkness. On day 20, mice were given to the second light exposure ( $30 \mathrm{~min}, 300$ lux at CT16). The first phase delay was presented as the difference between the onset time in the next day of light exposure and the onset time-fitted line from the days after light exposure. The second phase delay was presented as the difference between the onset time-fitted line from the days before and after light exposure of day 20.

Injection of PRV152 and AAV. GFP-expressing pseudorabies virus (PRV) 152, derived from Bartha strains, previously reported to label ipRGCs via local retinal circuits (Viney et al., 2007), was kindly provided by Lynn W. Enquist at Princeton University. All PRV procedures were conducted in biosafety level 2 laboratory and PRV injection of animals was approved by the Academia Sinica Environmental Health and Safety Committee and Institutional Animal Care and Utilization Committee (Taipei, Taiwan). PRV152 was amplified using a PK-15 cell line as de- 
scribed previously (Card and Enquist, 2014). R6/2 mice and their littermate controls aged 11 weeks were injected with $10^{5}$ plaque-forming units (pfus) $/ \mu$ l of PRV152 in DMEM into the anterior chamber of the right eye. After mice were anesthetized with the appropriate amounts of ketamine/xylazine, the cornea was stabbed to make a hole with a 30 gauge needle, and $1 \mu$ l of PRV152 was injected into the anterior chamber using a capillary glass pipette connected with a tubing-adapted $50 \mu$ l Hamilton syringe. For proper ipRGC labeling, mice were killed $5 \mathrm{~d}$ after injection via a fixation procedure of $4 \%$ paraformaldehyde in $0.1 \mathrm{M}$ phosphate buffer, $\mathrm{pH}$ 7.4. For subretinal injection of AAVs in adult mice, $1 \mu \mathrm{l}$ of AAV2/9-CB-Tbr2-IRES-EGFP $\left(5.8 \times 10^{12} \mathrm{vg} / \mathrm{ml}\right)$ or $2.5 \mu \mathrm{l}$ of AAV2/9CB-EGFP $\left(2.3 \times 10^{12} \mathrm{vg} / \mathrm{ml}\right)$ were injected into the subretinal space of the eye using a 33 gauge needle with a Hamilton syringe. Mice injected with AAVs at the age of 4 weeks were killed at the age of 10.5 weeks via a fixation procedure of $4 \%$ paraformaldehyde in $0.1 \mathrm{~m}$ phosphate buffer, pH 7.4.

RGC axon tracing. RGC axon labeling was performed as described previously (Sweeney et al., 2014). After mice were anesthetized by ketamine/xylazine (90-120 mg/kg; 5-10 mg/kg), $2 \mu \mathrm{l}$ of CTB-488 and CTB594 ( $1 \mu \mathrm{g} / \mu \mathrm{l}$; Invitrogen) were intravitreally injected to the right and left eye of individual mice using a capillary glass pipette (World Precision Instruments), which was connected to tubing adapted to a $50 \mu \mathrm{l} \mathrm{Hamil-}$ ton syringe with a KDS310 Nano Pump (KD Scientific), respectively. Three days after injection, mice were anesthetized and perfused with $4 \%$ paraformaldehyde in $0.1 \mathrm{M}$ phosphate buffer, $\mathrm{pH}$ 7.4. The cryopreserved coronal brain sections $(20 \mu \mathrm{m})$ of SCN, OPN, and LGN were collected for additional image analysis by inverted confocal plus super-resolution microscopy using a Zeiss LSM 780 plus ELYRA microscope.

In vivo apoptosis detection. A CAS-MAP in vivo probe, FAM-VADFMK (Vergent Bioscience) was used to detect apoptotic cells by binding to active caspases in vivo. Intravenous injection of FAM-VAD-FMK (100 $\mu \mathrm{l})$ was performed in lateral tail veins of each mouse. Then, mice were anesthetized $60 \mathrm{~min}$ after injection and fixed with $4 \%$ paraformaldehyde. Whole-mount retinas were isolated from each eyeball of the mice, which were subjected to immunohistochemical analysis. The activation of caspase (green signal) was imaged with an inverted confocal plus superresolution microscope (Zeiss LSM 780 plus ELYRA), and the number of apoptotic cells was determined.

Expression vector and melanopsin promoter preparation. The pcDNA3.1-HTT-23Q-hrGFP and pcDNA3.1-HTT-109Q-hrGFP constructs expressing exon 1 of human HTT protein with the indicated number of polyQ expansion fused to humanized Renilla green fluorescent protein (hrGFP) were described previously (Chiang et al., 2005). The melanopsin promoter fragments were isolated from C57BL/6 mouse genomic DNA via PCR and the primer sequences were as follows: The forward primer was 5'-CTAGCTAGCCGTGGGGCTAACAGAGA GAA-3', containing an NheI site, and reverse primers were used to determine different lengths of the melanopsin promoter region containing an KpnI site. The melanopsin promoter DNA fragment of $-1000 /+141$ was generated with the forward primer and 5'-GGGGTACCCTGTAATTTTGCTACTGTTATGAAC-3'; the melanopsin promoter DNA fragment of $-2000 /+141$ was generated with the forward primer and 5'-GGGGTACCACCCGATGACTACAGCTGCAGAG-3'; the melanopsin promoter DNA fragment of $-3000 /+141$ was generated with the forward primer and 5'-GGGGTACCTTCCCAGCTCCTCCCCTGG GCT- $3^{\prime}$. The PCR products were subcloned into the firefly luciferase reporter vector, pGL3-Basic vector (Promega), at NheI and KpnI sites. The pRL-TK vector, expressing Renilla luciferase, was used as an internal control reporter (Promega).

Luciferase assay. The measurement of luciferase activities in Neuro-2a cells (ATCC catalog \#CCL-131, RRID:CVCL_0470) is based on the manufacturer's protocol of the Dual-LuciferaseReporter Assay System (Promega) and was performed as described previously (Lin et al., 2013). Neuro-2a cells were grown in minimum essential medium (MEM) with $10 \%$ fetal bovine serum and $1 \%$ penicillin-streptomycin. Twenty-four hours before plasmid transfection, $\mathrm{N}_{2} \mathrm{~A}$ cells were plated into 6-well plates $\left(1 \times 10^{5}\right.$ cells/well $)$ and transiently transfected with pRL-TK vectors and either 23Q or 109Q hrGFP vectors and PGL3-Basic vectors constructed with different lengths of OPN4 promoter fragments at a ratio of 1:1:4 via Lipofectamine 2000 (Thermo Fisher Scientific). Luciferase activities were determined by a TD-20/20 Luminometer (Promega) and normalized to Renilla luciferase activities.

Statistical analyses. Statistical analyses were performed using GraphPad Prism software. Comparisons of mRNA levels, ipRGC numbers, RGC numbers, c-fos-positive cells, and fluorescence intensities of c-fos, Tbr2, and RBPMS between HD and control groups were analyzed by two-way ANOVA with Fisher's LSD test. Data of rotarod performance and body weight changes among groups were assessed by two-way ANOVA with Fisher's LSD test. The parameters of jet lag-phase shifting were analyzed by unpaired two-tailed $t$ tests and two-way ANOVA. The relative pupil sizes in pupillary light reflex (PLR) testing was analyzed by two-way ANOVA. $p$-values $<0.05$ were considered statistically significant.

\section{Results}

Specific reduction of ipRGC number during disease progression in mouse models of $\mathrm{HD}$ (R6/2 and N171-82Q)

According to previous studies, mutant HTT aggregates are detected in the nucleus of the photoreceptor layer and RGC layer in mouse models of HD (Helmlinger et al., 2002; Hamada et al., 2004), indicating that mutant HTT aggregates exist in several types of neurons in the retina. However, whether ipRGCs express mutant HTT is still unknown. Using anti-brn3a or melanopsin antibodies, which labeled regular RGCs and ipRGCs, respectively, and an EM48 antibody, which labeled mutant HTT aggregation, our triple immunostaining showed that mutant HTT aggregates were detected in both ipRGCs and RGCs in the R6/2 mouse model of $\mathrm{HD}$ at a symptomatic stage (10.5 weeks) (Fig. 1A). In R6/2 mice, expression of mutant HTT is driven by the human $h t t$ promotor and is expressed in many different cell types (including neurons and glia). The motor function deficiency of R6/2 mice can be detected at 10 weeks by rotarod performance (two-way ANOVA with interaction, $F_{(6,114)}=4.02, p=0.0011$, difference at 10 weeks, $\left.t_{(114)}=3.45, p=0.005\right)$ and decreased body weight (two-way ANOVA with interaction, $F_{(6,98)}=4.02$, $p<0.0001$, difference at 10 weeks, $t_{(98)}=5.89, p<0.0001$; Fig. $1 H, I)$. To determine whether ipRGCs are involved in the circadian disruption in HD, we first evaluated the number of ipRGCs in R6/2 mice during disease progression at the ages of 4, 7, 10.5, and 12 weeks. In contrast to no change in the number of $\mathrm{Brn3a}(+)$ RGCs during disease progression (two-way ANOVA, $F_{(1,20)}=0.06, p=0.796$; Fig. $\left.1 D, G\right)$, we observed significantly lower numbers of melanopsin-immunoreactive ipRGCs at the symptomatic stage ( 10.5 and 12 weeks) compared with an early presymptomatic stage ( 4 or 7 weeks) (two-way ANOVA, $F_{(3,43)}=10.71$, $p<0.0001$, post hoc 4 vs 10.5-week-old R6/2 mice, $t_{(43)}=5.58, p<$ 0.0001 , post hoc 7 vs 10.5-week-old R6/2 mice, $t_{(43)}=2.21, p=$ 0.03 ; Fig. $1 B, E)$. Surprisingly, the number of ipRGCs in 7 -weekold R6/2 mice, which is before the onset of detectable motor dysfunction, was also significantly lower than in 4-week-old mice (two-way ANOVA, post hoc 4- vs 7-week-old R6/2 mice, $t_{(43)}=$ $3.11, p=0.003$; Fig. $1 E$ ). The reduced number of melanopsinimmunoreactive ipRGCs was similarly observed in another HD mouse model, N171-82Q mice (two-way ANOVA, $F_{(1,20)}=$ $0.854, p=0.366$, post hoc 16-week-old N171-82Q vs control, $t_{(20)}=2.42, p=0.024$; Fig. $\left.1 C, F\right)$, with N-terminally truncated human HTT expressed only in neurons (Schilling et al., 1999), which suggests that neuronal mutant HTT is able to affect melanopsin expression in ipRGCs, although the phenotype in N171$82 \mathrm{Q}$ mice is milder than in $\mathrm{R} 6 / 2$ mice. Therefore, our data indicate that mutant HTT specifically affects ipRGCs in the retina at early stages of HD. 

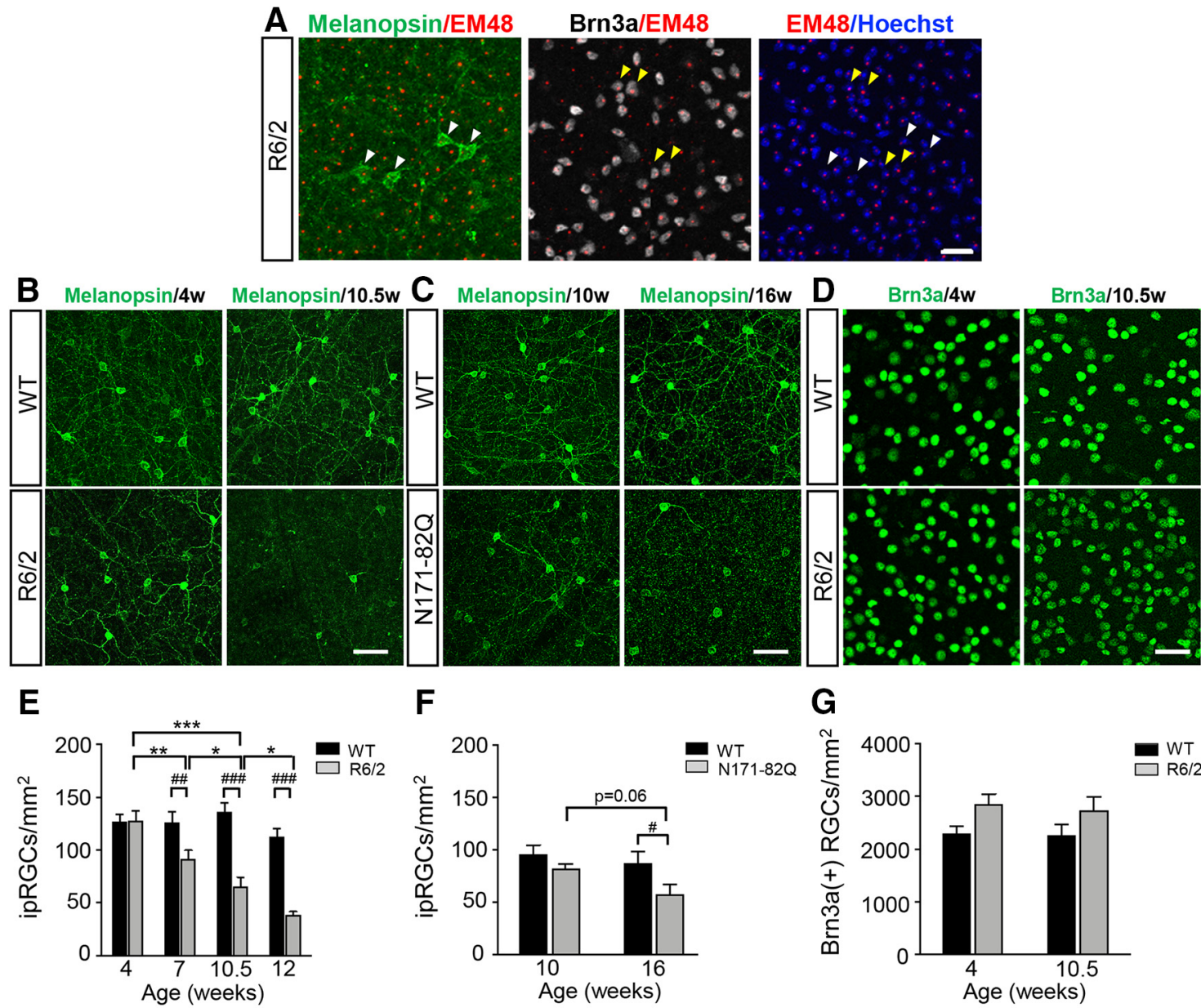

$\mathbf{F}$

\section{G}
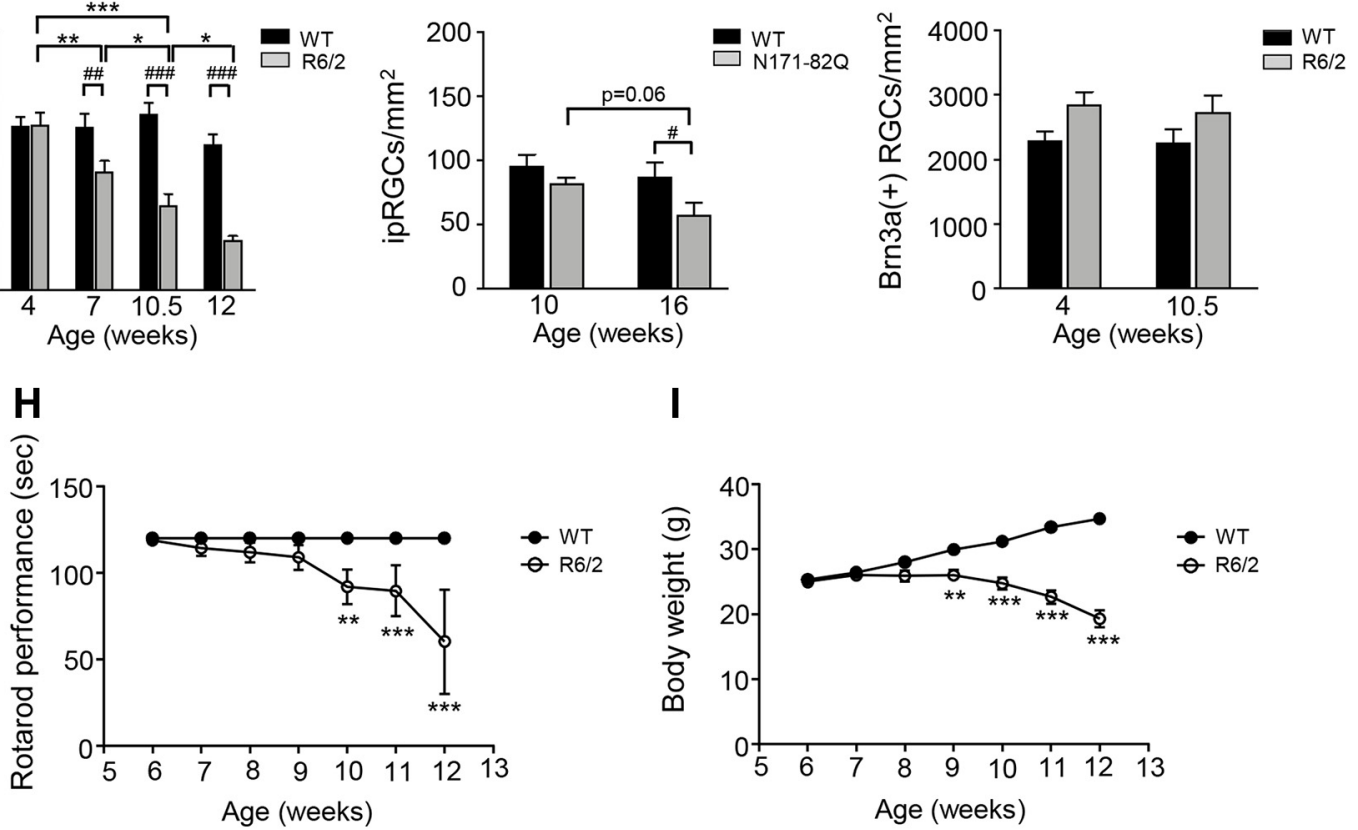

Figure 1. Longitudinal decreases in ipRGC numbers in mouse models of HD before motor dysfunction. A, Triple immunostaining of RGCs by antibodies against melanopsin, Brn3a and mutant HTT (EM48) in 10.5-week-old R6/2 mice. Melanopsin-positive ipRGCs showed the expression of mutant HTT labeled by EM48 antibodies (left image). The expression of mutant HTT was also observed in Brn3a-positive RGCs (middle image). The right image shows the distribution of mutant HTT aggregates in GCL. $\boldsymbol{B}$ - $\boldsymbol{D}$, Representative images of melanopsin-positive ipRGCs in retinas of R6/2 (B) and N171-82 ( $($ ) mice and Brn3a-positive RGCs in retinas of R6/2 mice (D) of the indicated ages. $\boldsymbol{E}-\boldsymbol{G}$, The number of ipRGCs was determined in $R 6 / 2(\boldsymbol{E})$ and N171-82Q $(\boldsymbol{F})$ mice of the indicated ages $(n=$ 3-5 for each group). G, Quantification of RGCs in R6/2 mice ( $n=3$ for each group). $\boldsymbol{H}$, Rotarod performance of the indicated mice at age of 6 weeks was recorded for 6 weeks. Mice were tested on a rotating rod at a speed of $12 \mathrm{rpm}$ over a $120 \mathrm{~s}$ period. The duration that mice remained on the rotating rod was recorded. $I$, Body weight changes of these mice were measured from 6 to 12 weeks. The test groups included R6/2 mice $(n=11)$ and control mice $(n=9)$. Scale bars: $A, 20 \mu \mathrm{m} ; \boldsymbol{B}, \boldsymbol{D}, 50 \mu \mathrm{m} ; \boldsymbol{F}, 25 \mu \mathrm{m}$. Data are presented as the means \pm SEM. ${ }^{*} p<0.05$, ${ }^{* *} p<0.01,{ }^{* * *} p<0.001$; $\# p<0.05$, \#\#p $<0.01$, \#\#\# <0.001 compared with age-matched controls, two-way ANOVA.

M1 ipRGCs are vulnerable in HD mice (R6/2) at the symptomatic stage

To evaluate whether distinct subtypes of ipRGCs are influenced by HD differentially, we first measured the melanopsin-positive processes of M1 or non-M1 ipRGCs, which stratified primarily within the OFF or ON sublamina in the inner plexiform layer (IPL), respectively (Fig. $2 A, C$ ). At the early presymptomatic stage, there was no change in the melanopsin-positive processes at the OFF and ON sublamina of IPL (two-way ANOVA, post hoc 4-week-old R6/2 vs WT in OFF sublamina, $t_{(95)}=0.99, p=0.32$, post hoc 4-week-old R6/2 vs WT in ON sublamina, $t_{(96)}=1.438$, $p=0.15$; Fig. $2 B, D)$. However, at the symptomatic stage, the reductions of melanopsin-positive processes were detected at both ON (two-way ANOVA in ON sublaminae, $F_{(2,96)}=40.41$, $p<0.0001$, post hoc 10.5-week-old R6/2 vs WT, $t_{(96)}=13.37, p<$ 0.0001 ) and OFF sublaminae of IPL (two-way ANOVA in OFF sublaminae, $F_{(2,95)}=15.36, p<0.0001$, post hoc 10.5-week-old R6/2 vs WT, $t_{(95)}=6.78, p<0.0001$; Fig. $\left.2 B, D\right)$, suggesting that 

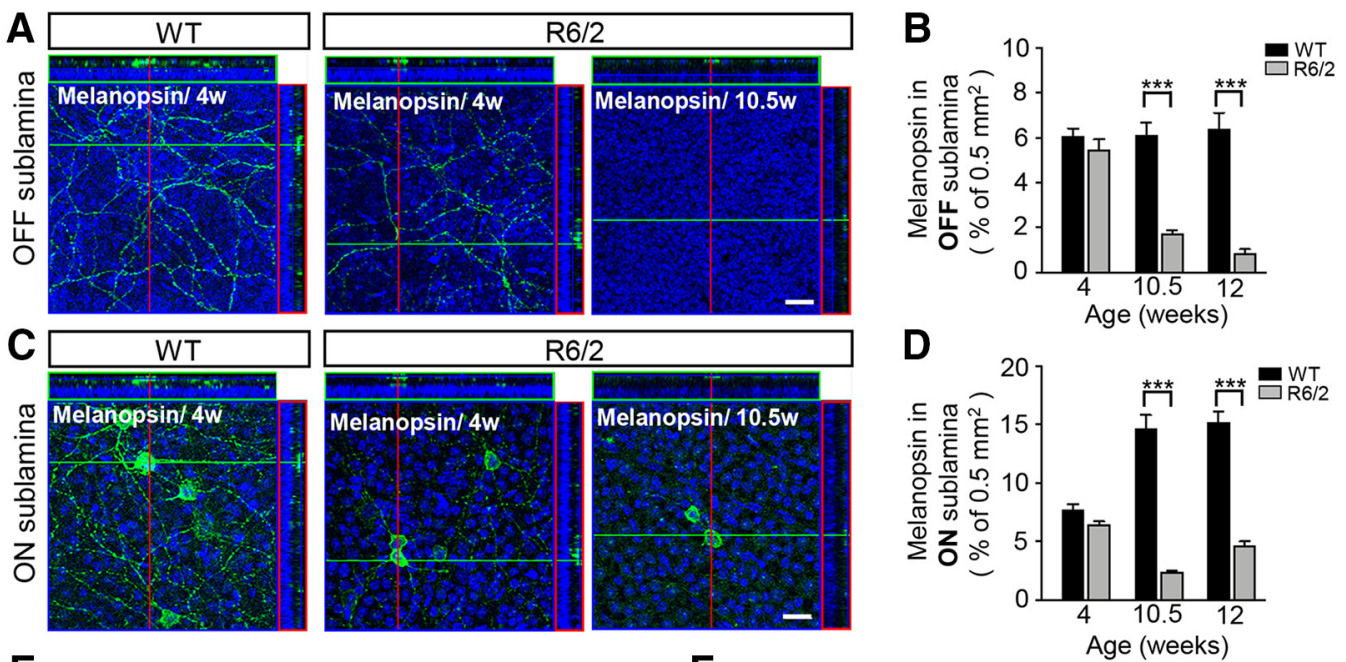

X-gal

$\mathbf{F}$

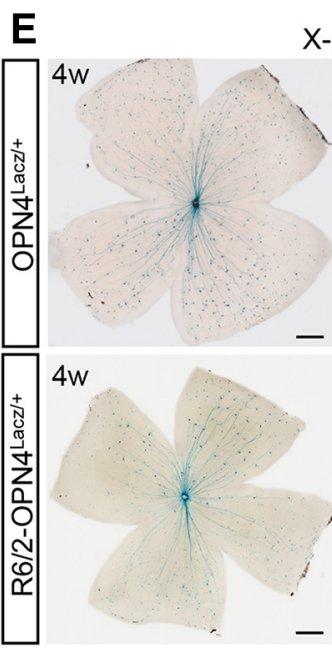

G
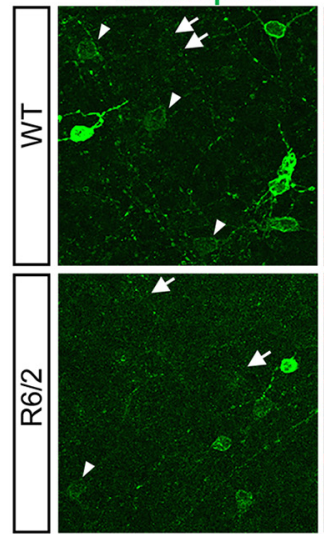

$12 \mathrm{w}$

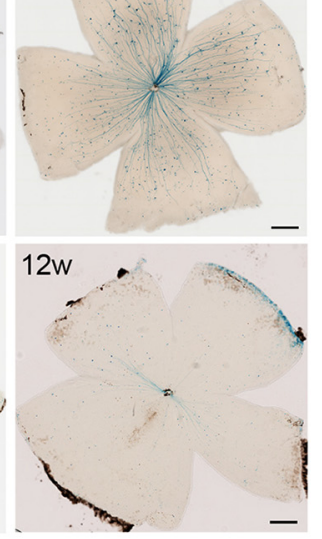

Smi-32

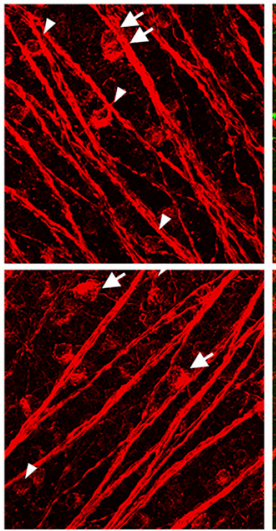

Melanopsin/Smi-32

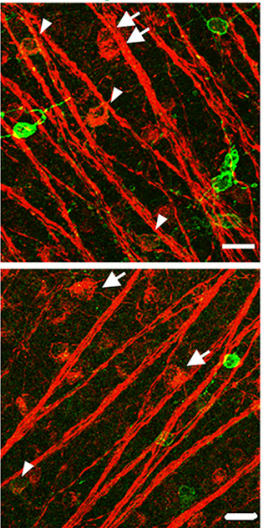

H
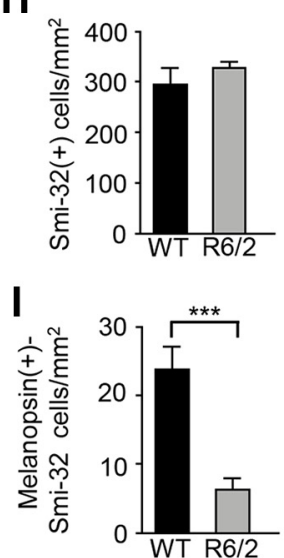

Figure 2. Alteration of M1-ipRGCs and non-M1 ipRGCs in R6/2 mice at the symptomatic stage. $A, C$, Representative confocal images showing the changes of melanopsin-labeled processes in the OFF $(\boldsymbol{A})$ and $0 \mathrm{~N}(\boldsymbol{C})$ sublaminae of the IPL in 4- and 10.5-week-old R6/2 mice compared with control mice at the indicated ages. $\boldsymbol{B}, \boldsymbol{D}$, Distribution of melanopsin in the $0 \mathrm{FF}(\boldsymbol{B})$ and $0 \mathrm{~N}(\boldsymbol{D})$ sublaminae of IPL in the indicated mice at the different ages were measured by Fiji software and the expression levels of somatic and dendritic melanopsin relative to a retinal area $\left(0.5 \mathrm{~mm}{ }^{2}\right)$ are presented; in an individual mouse, 6 retinal areas were randomly selected for the quantification ( $n=3$ for each group). $E$, X-gal-labeled ipRGCs in the retinas of OPN4 ${ }^{\text {Lacz/ }+}$ and R6/2-OPN4 ${ }^{\text {Lacz/ }+}$ mice at the ages of 4 and 12 weeks are shown. $\boldsymbol{F}$, Bar graph presenting total X-gal-labeled M1-ipRGCs in R6/2-0PN4 ${ }^{\text {Lac } /+}$ ( 4 weeks, $n=3 ; 12$ weeks, $\left.n=3\right)$ and 0PN4 ${ }^{\text {Lacz } /+}$ mice $(4$ weeks, $n=5 ; 12$ weeks, $n=$ 4). G, Representative images showing melanopsin-positive ipRGCs with smi-32 immunoreactivity (arrowheads) and the smi-32-positive, melanopsin-negative RGCs (arrows) in the indicated mice at the age of 12 weeks. $\boldsymbol{H}$, Numbers of Smi-32(+) cells were calculated in R6/2 and control retinas, $n=3$ for each group. $\boldsymbol{I}$, Numbers of cells immunoreactive for melanopsin/smi- 32 in R6/2 retinas were lower than in control mice $\left(n=3\right.$ for each group). Scale bars: $A, C, G, 20 \mu \mathrm{m} ; \boldsymbol{E}, 500 \mu \mathrm{m}$. Data are presented as the means \pm SEM. ${ }^{* *} p<0.01$, ${ }^{* * *} p<0.001$, two-way ANOVA and unpaired $t$ test. ON sublamina, bottom part of the IPL; OFF sublamina, upper part of the IPL.

M1 and non-M1 ipRGCs are both affected in R6/2 mice. To further verify the disease-induced alteration in the indicated ipRGC subtypes, we crossed OPN4 ${ }^{\mathrm{Lacz} /+}$ mice with R6/2 mice to analyze M1 ipRGCs. The number of M1 cells labeled by X-gal from R6/2-OPN $4^{\mathrm{Lacz} /+}$ mice was significantly lower than control mice at the symptomatic stage (two-way ANOVA, $F_{(1,14)}=1.52$, $p=0.23$, post hoc 4 -week-old R6/2 vs WT, $t_{(14)}=1.58, p=0.13$, post hoc 12-week-old R6/2 vs WT, $t_{(14)}=3.65, p=0.002$; Fig. 

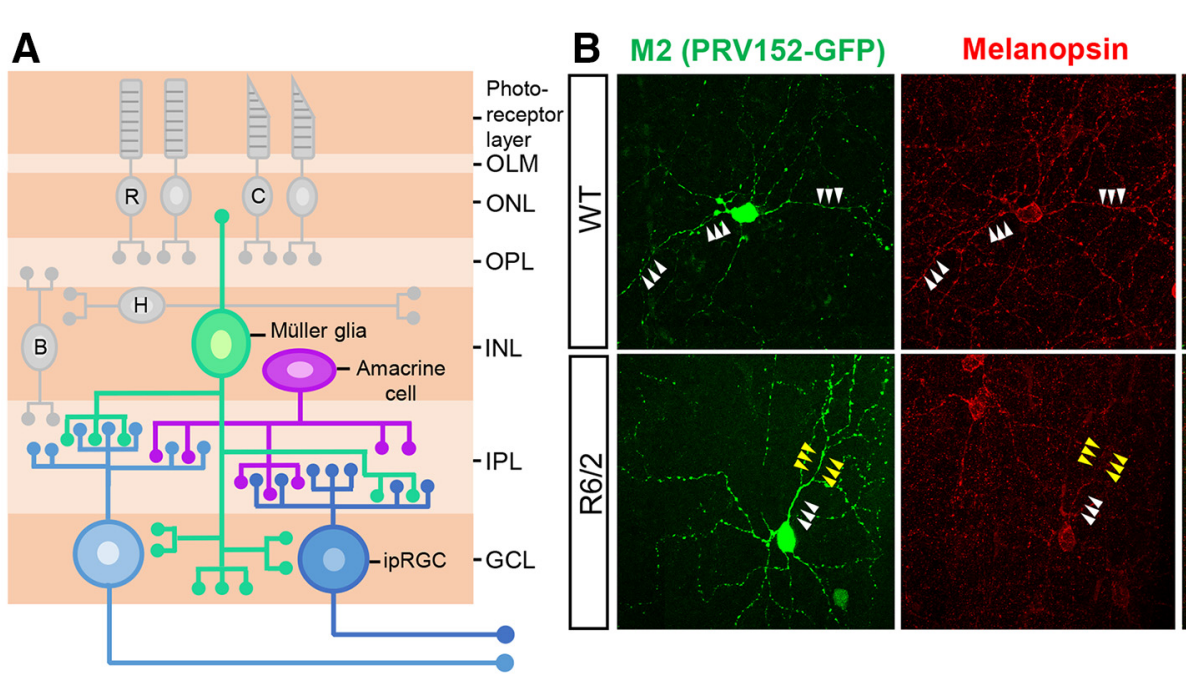

M2 (PRV152-GFP)/ Melanopsin
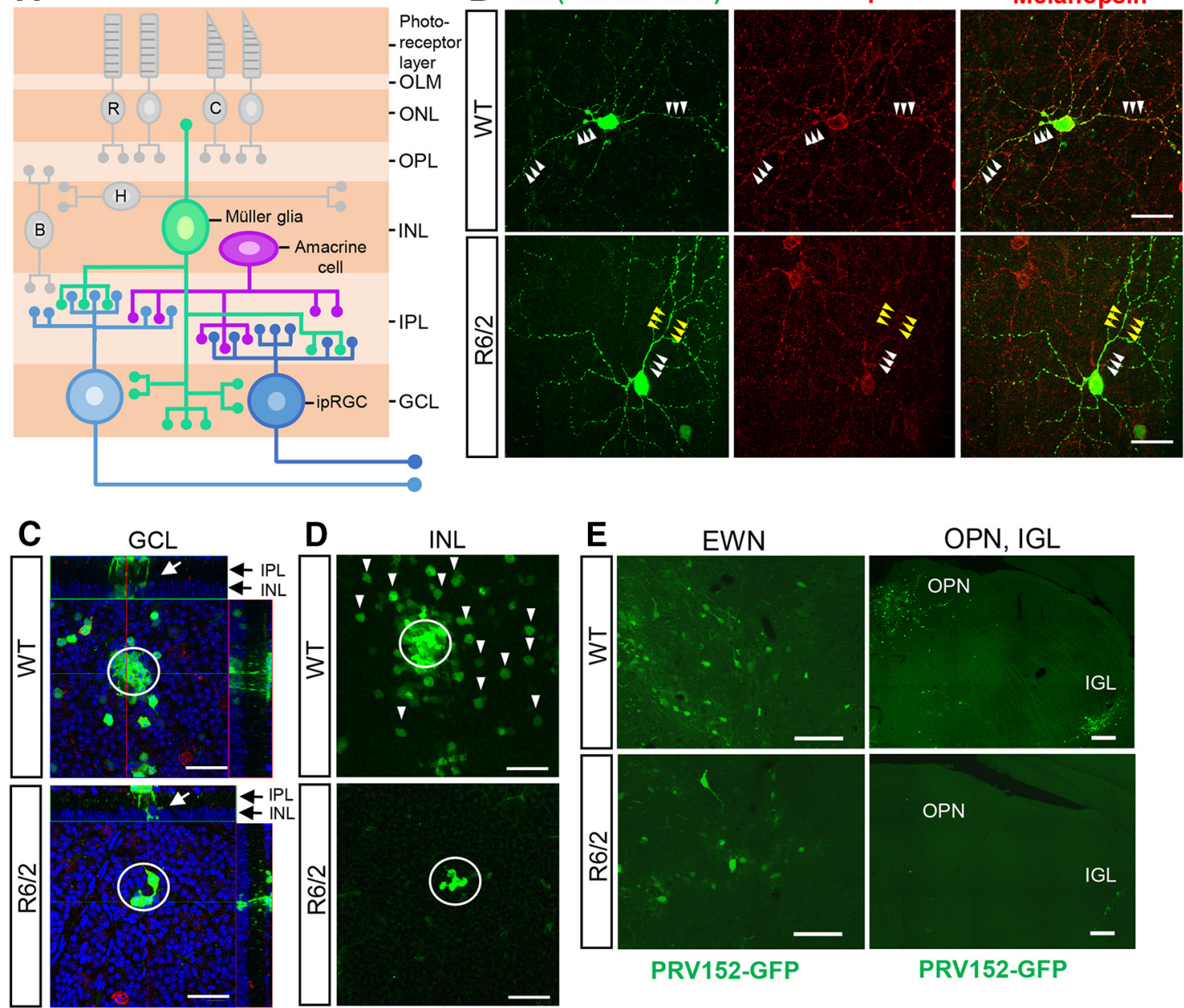

PRV152-GFP/

Melanopsin/

PRV152-GFP

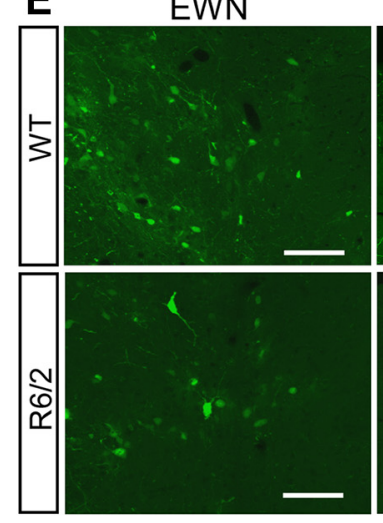

PRV152-GFP

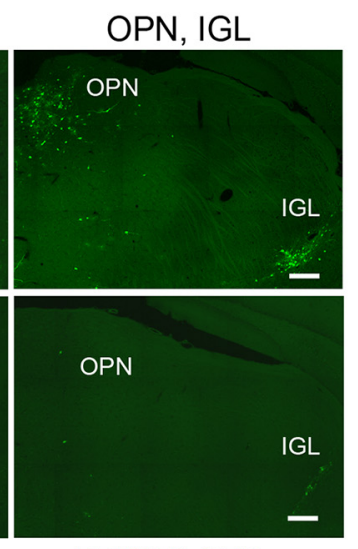

PRV152-GFP

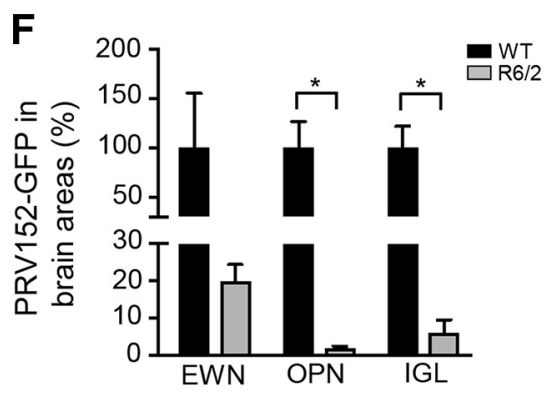

Figure 3. Analysis of local synaptic connections of ipRGCS and PLR circuits via PRV152 retrograde tracing. $\boldsymbol{A}$, Illustration of the synaptic connections of Müller glia and amacrine cells with ipRGCS as described previously (Viney et al., 2007). B, After $5 \mathrm{~d}$ PRV152 infections, PRV152-infected ipRGCs expressing GFP in both the soma and dendrites were identified in the noninjected retina in 12-week-old mice. Representative images showing that the dendritic expression of melanopsin, labeled by anti-melanopsin antibodies, in PRV152-labeled M2 ipRGCs was lower in R6/2 mice relative to control mice. The dendrite region with melanopsin expression is indicated by a white arrowhead; the dendrite region without melanopsin expression is indicated by yellow arrowheads. $\boldsymbol{C}$, The Müller glia labeled by PRV152 in the indicated mice are shown as a cluster of GFP expression (white circle) in GCL and are indicated by arrows in the $z$-axis view. $\boldsymbol{D}$, In the same $x-y$ axis of $\boldsymbol{C}$ in INL, amacrine cells (GFP, arrowhead) labeled by PRV152 were obtained in control mice, but not in R6/2 mice. $\boldsymbol{E}$, Representative images showing the PRV152-infected neurons with GFP expression in EWN, OPN, and IGL in 12-week-old R6/2 mice and control mice. ( $n=3-5$ for the indicated mice). $\boldsymbol{F}$, Total PRV152-GFP expression levels in EWN, 0PN, and IGL ( $n=3-5$ for the indicated mice). Scale bars: $\boldsymbol{B}, 50 \mu \mathrm{m} ; \boldsymbol{C}, \boldsymbol{D}, 40 \mu \mathrm{m} ; \boldsymbol{E}, 100 \mu \mathrm{m}$. Data are presented as the means \pm SEM. ${ }^{*} p<0.05$, unpaired $t$ test. R, Rod photoreceptor; $\boldsymbol{C}$, cone photoreceptor; $B$, bipolar cell; $H$, horizontal cell; INL, inner nuclear layer; EWN, Edinger-Westphal nucleus.

$2 E, F)$, confirming that M1 ipRGCs are highly vulnerable in HD. Specifically, M4 ipRGCs can be labeled by an anti-200 kDa neurofilament heavy chain (Smi-32) antibody, which is a marker for ON and OFF $\alpha$ RGCs that innervate LGN for image-forming functions (Schmidt et al., 2014). However, the number of M4 cells was unaffected at 12 weeks (unpaired $t$ test, $t_{(10)}=0.97, p=$ 0.350; Fig. $2 G, H$ ). The melanopsin immunoreactivity reduction in Smi-32 (+) cells suggested the intrinsic properties to light of
M4 cells might be changed (unpaired $t$ test, $t_{(10)}=5.01, p=$ 0.0005; Fig. 2I).

In Figure 3, we analyzed PLR circuit and local retinal circuit from ipRGC (Fig. $3 A$ ) by polysynaptic circuit tracing with pseudorabies virus to confirm the loss of ipRGCs. The GFPexpressing pseudorabies virus Bartha strain (PRV152) was delivered into the anterior chamber of one eyeball (Viney et al., 2007). The GFP signals in the retina of non-injected eyeball and 


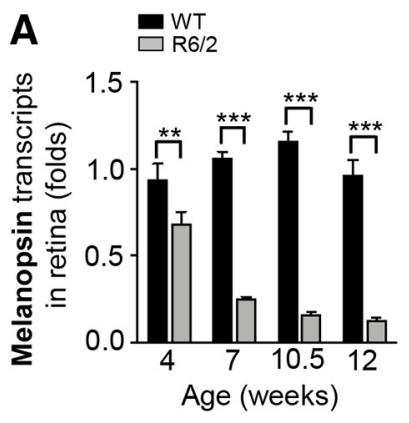

D

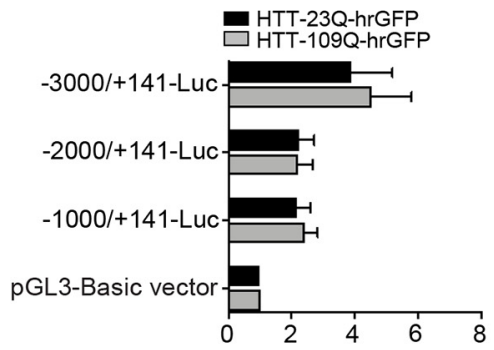

Relative luciferase activity (folds)
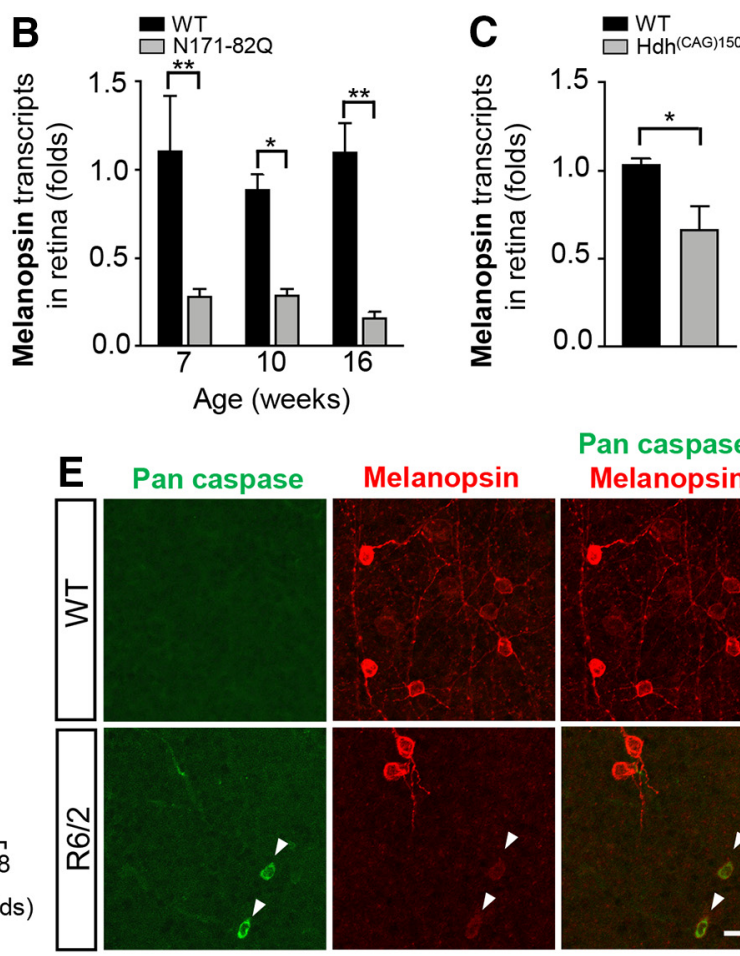

Pan caspase Melanopsin

$F$
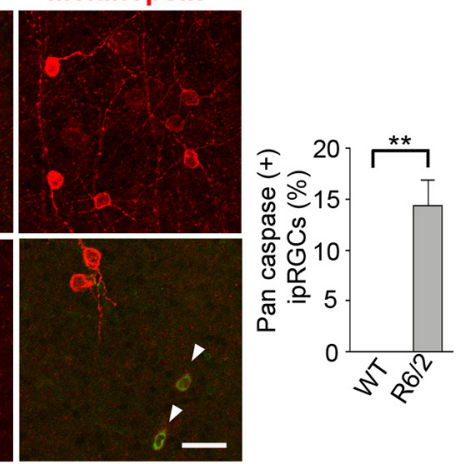

G

Melanopsin

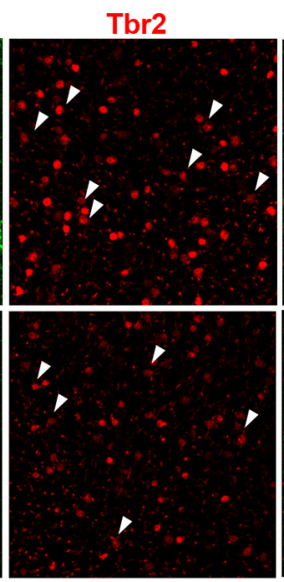

Melanopsin/Tbr2
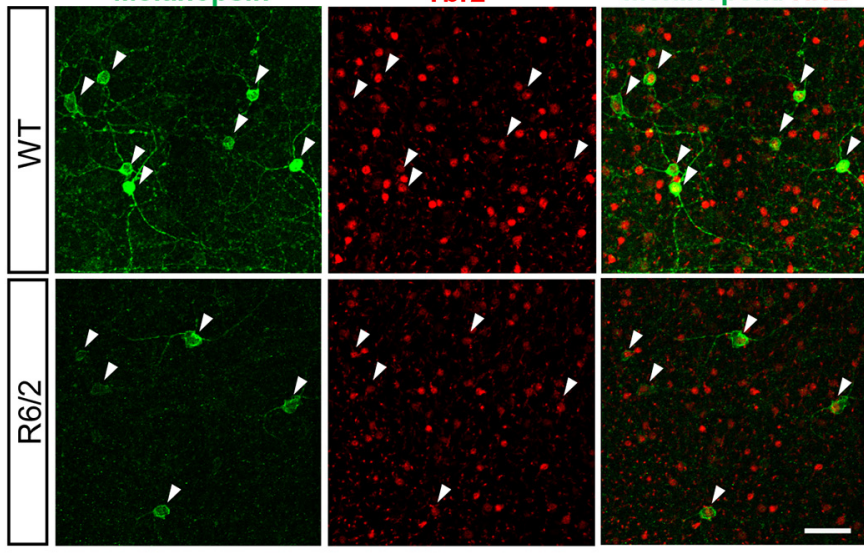

J Melanopsin

RBPMS

Melanopsin/ RBPMS
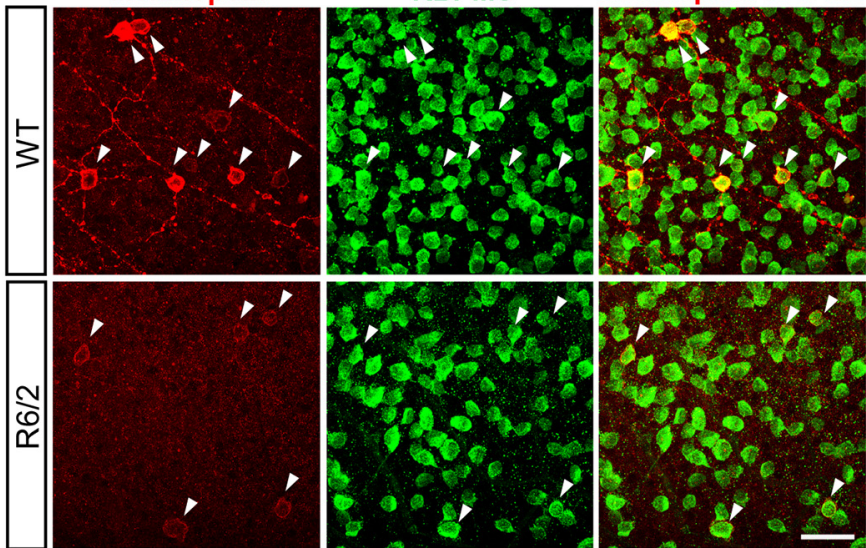

H
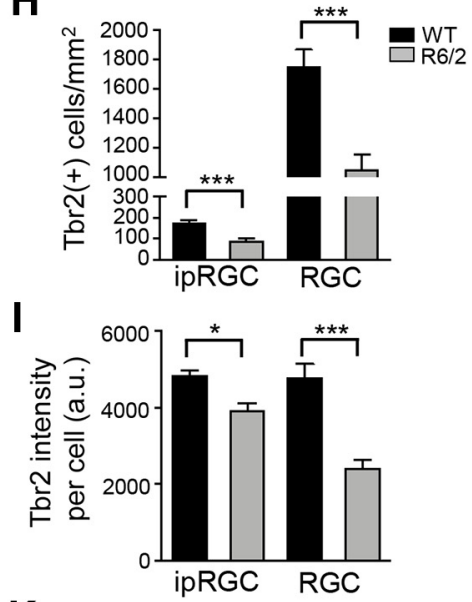

K

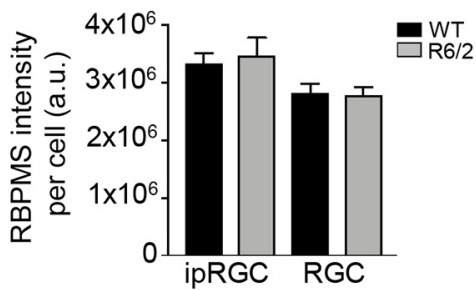

Figure 4. Downregulation of melanopsin expression and ipRGC numbers through Tbr2 and apoptosis in mouse models of HD. $A-C$, Transcript levels of melanopsin in the retinas of R6/2 mice $(n=$ $3-6 ; A), \mathrm{N} 171-82 \mathrm{Q}$ mice $(n=3 ; \boldsymbol{B})$ at the indicated ages, and homozygous $\mathrm{Hdh}{ }^{(\mathrm{CAG}) 1500}$ mice at the age of 15 months $(n=3 ; \boldsymbol{B})$ were compared with age-dependent littermate controls. $\boldsymbol{D}, \mathrm{N}_{2} \mathrm{~A}$ cells were simultaneously transfected with a pGL3-Basic vector carrying different lengths of melanopsin promoter regions plus HTT-23Q-hrGFP or HTT-109Q-hrGFP and pRL-TK vector ( $n=3$ ). The luciferase activity was detected in transfected $\mathrm{N}_{2} \mathrm{~A}$ cells $48 \mathrm{~h}$ after transfection. The relative luciferase activity is presented as the original value divided by the value detected in the $\mathrm{pGL} 3$-Basic vector with the Htt-23Q-hrGFP group. E, Confocal images show ipRGCs positive for pan-caspase in 12-week-old R6/2 mice in vivo labeled by the CAS-MAP probe (FAM-VAD-FMK, green). The pan-caspaseexpressing ipRGCs were considered apoptotic cells. $\boldsymbol{F}$, Percentage of pan-caspase $(+)$ ipRGCs in the indicated mice was obtained from the number of pan-caspase $(+)$ (Figure legend continues.) 
the brain were analyzed. Surprisingly, we found no M1 ipRGCs labeled by PRV152 in R6/2 mice $(n=3)$, compared with WT mice (1.35 \pm 0.26 from $0.6 \mathrm{~mm}^{2}$ of retina in WT; $\left.n=7\right)$. Furthermore, we found that M2 ipRGCs in HD mice (R6/2) had lower dendritic melanopsin expression than that of control mice (Fig. 3B). Note that there were fewer M2 ipRGCs in R6/2 mice relative to WT mice (M2 ipRGCs: $3 \pm 0.79$ from $0.6 \mathrm{~mm}^{2}$ of retina in WT, $n=7 ; 0.66 \pm 0.47$ from $0.6 \mathrm{~mm}^{2}$ of retina in $\mathrm{R} 6 / 2$, $n=3$ ). M3 ipRGCs seemed to not be affected in R6/2 mice (M3 ipRGCs: $0.28 \pm 0.12$ from $0.6 \mathrm{~mm}^{2}$ of retina in WT, $n=7 ; 0.22 \pm$ 0.44 from $0.6 \mathrm{~mm}^{2}$ of retina in $\mathrm{R} 6 / 2, n=3$ ). The synaptic connections of Müller glia and amacrine cells with ipRGCs as described previously (Viney et al., 2007) (Fig. 3A). Here, we showed that fewer Müller glia (Fig. 3C) as well as amacrine cells (Fig. 3D) were labeled by PRV152 in R6/2 mice relative to WT mice, which confirmed that the connectivity from ipRGC in the retina was reduced. Furthermore, the OPN and intergeniculate leaflet (IGL) within the PLR circuit in R6/2 mice showed lower GFP expression relative to WT mice (unpaired $t$ test, $\mathrm{EWN}, t_{(5)}=1.232, p=$ 0.27 , OPN $t_{(5)}=3.154, p=0.025$, IGL, $t_{(5)}=3.652, p=0.014$; Fig. $3 E, F)$, suggesting that the PLR circuit might be impaired after ipRGC degeneration. Together, our results suggest that M1 ipRGCs and the M1-mediated PLR circuitry are the most vulnerable, whereas non-M1 ipRGCs, at least M3 and M4 cells, are comparatively resilient to HD progression.

\section{Downregulation of Tbr2, an essential transcription factor for ipRGC, and apoptosis of ipRGC in the retina of HD mice $(\mathrm{R} 6 / 2)$}

Because immunostaining of ipRGC relied on the expression of melanopsin, the reduced numbers of ipRGC in HD mice could be due to reduced expression of melanopsin or ipRGC cell death. First, using qRT-PCR from the whole retina, we found a progressive reduction in melanopsin transcript levels in R6/2 (unpaired $t$ test, comparing R6/2 mice with age-matched controls, 4 weeks, $t_{(22)}=2.90, p=0.007,7$ weeks, $t_{(22)}=10.14, p<0.0001,10.5$ weeks, $t_{(22)}=11.67, p<0.0001,12$ weeks, $t_{(22)}=13.26, p<$ 0.0001 ; Fig. $4 A$ ) and N171-82Q mice (unpaired $t$ test, comparing N171-82Q mice with age-matched controls, 7 weeks, $t_{(12)}=3.90$, $p=0.002,10$ weeks, $t_{(12)}=2.83, p<0.0001,16$ weeks, $t_{(12)}=$ $4.46, p=0.0007$; Fig. $4 B$ ). The levels of melanopsin transcript in R6/2 mice were significantly lower than controls even at 4 weeks of age, when the number of ipRGCs showed no difference between R6/2 and control mice (Fig. 4A). Furthermore, the reduction in melanopsin transcripts was also observed in a full-length mutant HTT knock-in HD mouse, $\mathrm{Hdh}^{(\mathrm{CAG}) 150 \mathrm{Q}}$ (unpaired $t$ test, $t_{(4)}=2.80, p=0.04$; Fig. $\left.4 C\right)$. $\mathrm{Hdh}^{(\mathrm{CAG}) 150 \mathrm{Q}}$ mice have more subtle behavioral and neuropathological features compared with

$\leftarrow$

(Figure legend continued.) ipRGCs divided by the number of ipRGCs that were counted. (WT: no pan-caspase (+) ipRGCs in $87 \pm 9.29 \mathrm{ipRGCs}, n=3 ; R 6 / 2$ : $14.2 \pm 3.48$ pan-caspase $(+)$ ipRGCs in $94.4 \pm 12.64$ ipRGCs, $n=5$ ). $G$, Images showing the detection of Tbr 2 in the nuclei of ipRGCs (arrowhead) by anti-melanopsin and anti-Tbr2 antibodies in the 12-week-old mice. $\boldsymbol{H}$, Numbers of Tbr2-positive ipRGCS and RGCS obtained from the indicated mice. $\boldsymbol{I}$, Fluorescence intensities of Tbr 2 in ipRGCs and RGCs of the indicated mice at the age of 12 weeks measured by ImageJ software. J, Images showing that RBPMS in the cytoplasmic regions of ipRGCS (arrowhead) was detected by anti-melanopsin and anti-RBPMS antibodies in 12-week-old mice. $\boldsymbol{K}$, Fluorescence intensity of RBPMS per ipRGC (arrowhead) and RGC in 12-week-old mice quantified by ImageJ software (4 retinal areas per mouse were randomly selected for the quantification in $\boldsymbol{H}, \boldsymbol{I}$, and $\boldsymbol{K}$ ( $n=3-4$ for each group of mice). Scale bars: $\boldsymbol{E}, 30 \mu \mathrm{m} ; \boldsymbol{G}, 50 \mu \mathrm{m} ; \boldsymbol{J}, 40$ $\mu \mathrm{m}$. Data are presented as the means \pm SEM. ${ }^{*} p<0.05,{ }^{* *} p<0.01$, ${ }^{* * *} p<0.001$, unpaired $t$ test. mutant HTT transgenic mice (Lin et al., 2001), suggesting the overall effect of mutant HTT on melanopsin expression. To determine whether mutant HTT can directly regulate melanopsin transcription, the activity of the melanopsin promoter from 1-3 $\mathrm{kb}$ upstream of exon 1 of the mouse melanopsin gene was assessed in vitro by luciferase assay in Neuro-2a cells. The melanopsin promoter activities were not disrupted when cells were cotransfected with HTT-109Q-hrGFP, as opposed to those in HTT-23Q-hrGFP-transfected groups (unpaired $t$ test; Fig. 4D), suggesting that melanopsin downregulation via mutant HTT expression does not occur through transcriptional regulation at the proximal promoter region. We next evaluated whether ipRGCs undergo apoptosis during HD progression. Using the pancaspase inhibitor-conjugated FAM as an in vivo marker of apoptosis, we observed that $\sim 15 \%$ of ipRGCs in R6/2 mice at the symptomatic stage were positive for the apoptosis marker, in contrast to ipRGCs from control mice (unpaired $t$ test, $t_{(6)}=$ $4.22, p=0.005$; Fig. $4 E, F)$, indicating that ipRGCs undergo apoptosis during HD progression. Recent studies have reported that Tbr2 (also called Eomes) in the retina is required for the formation and survival of ipRGCs (Mao et al., 2014; Sweeney et al., 2014). Here, we speculate that Tbr2 is a downstream target of mutant HTT that leads to ipRGC degeneration. We found a reduced number of Tbr2-expressing RGCs and ipRGCs in the ganglion cell layer (GCL) of R6/2 retina compared with WT retina (unpaired $t$ test for ipRGC, $t_{(29)}=5.81, p<0.0001$; for RGC, $t_{(30)}$ $=4.60, p<0.0001$; Fig. $4 G, H)$. Furthermore, the fluorescence intensity of Tbr2 per ipRGC and RGC in R6/2 mice was lower than that of WT mice (unpaired $t$ test for ipRGC, $t_{(30)}=2.453$, $p=0.02$; for RGC, $t_{(30)}=5.79, p<0.0001$; Fig. $\left.4 I\right)$. There was no difference in the fluorescence intensity of the RNA-binding protein with multiple splicing (RBPMS, a specific ganglion cell marker; Rodriguez et al., 2014) per ipRGC and RGC between $\mathrm{R} 6 / 2$ and control mice (unpaired $t$ test for ipRGC, $t_{(25)}=0.362$, $p=0.72$; for RGC, $t_{(25)}=0.141, p=0.88$; Fig. $\left.4 \mathrm{~J}, K\right)$. Therefore, our data suggested that mutant HTT may influence melanopsin expression and ipRGC survival through Tbr2.

\section{Tbr2 restores melanopsin expression in HD mice (R6/2)}

To evaluate whether Tbr2 is involved in mutant HTT-mediated melanopsin downregulation and ipRGC survival, we exogenously expressed Tbr2 in RGCs through injection of adeno-associated viruses (AAVs) expressing Tbr2 (AAV2/9-CB-Tbr2-IRES-EGFP, AAV-Tbr2) or EGFP control (AAV2/9-CB-EGFP, AAV-EGFP) in the subretinal space of eye in mice at 4 weeks (Lei et al., 2009, 2010). Six weeks after infection, the numbers of Tbr2(+) cells in the GCL in the AAV-Tbr2 group showed $\sim 30 \%$ increases compared with the AAV-EGFP group in both WT mice and R6/2 mice (two-way ANOVA, $F_{(1,47)}=0.06, p=0.79$, post hoc AAV-Tbr2and AAV-EGFP-infected WT mice, $t_{(47)}=3.01, p=0.004$, post hoc AAV-Tbr2- and AAV-EGFP-infected R6/2 mice, $t_{(47)}=3.46$, $p=0.001$; Fig. $5 A, B)$. When compared with AAV-EGFPinfected R6/2 mice, the Tbr2 fluorescence intensities in RGCs and ipRGCs were significantly enhanced in AAV-Tbr2-infected R6/2 mice (two-way ANOVA in RGC, $F_{(1,47)}=1.65, p=0.20$, post hoc AAV-Tbr2- and AAV-EGFP-infected R6/2 mice, $t_{(47)}=3.57, p=$ 0.0008; two-way ANOVA in ipRGC, $F_{(1,46)}=4.77, p=0.03$, post hoc AAV-Tbr2- and AAV-EGFP- infected R6/2 mice, $t_{(46)}=3.21$, $p=0.002$; Fig. $5 A, C)$. However, Tbr2 overexpression in WT retina did not further increase Tbr2 expression per cell. We next determined the melanopsin fluorescence intensity per ipRGC and ipRGC to assess the rescue effect of Tbr2 overexpression. Exogenous expression of Tbr2 significantly elevated the mel- 
A
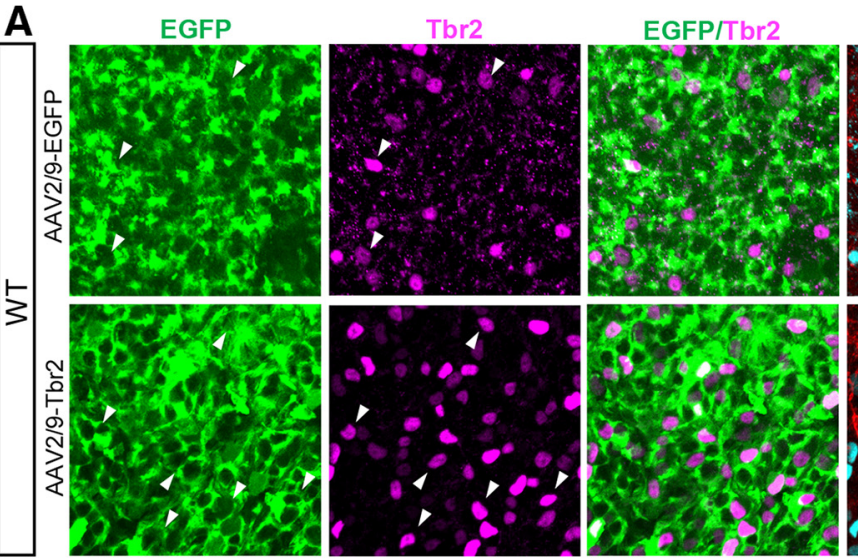

Melanopsin/Tbr2
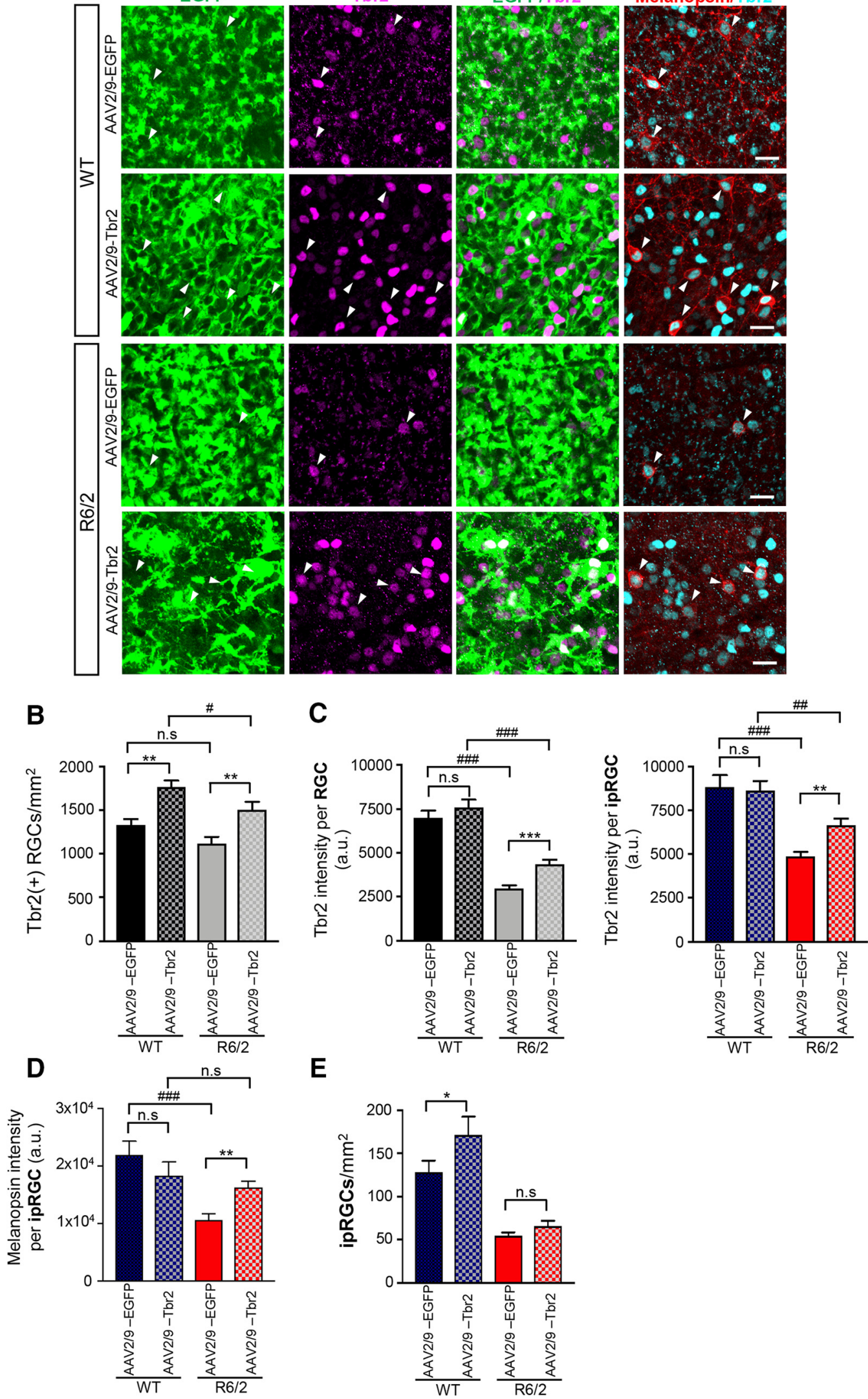

E

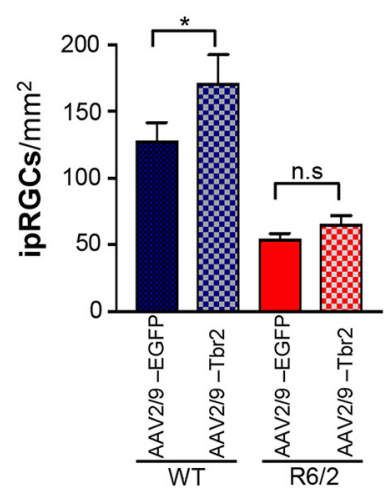

Figure 5. Requirement of Tbr2 for melanopsin renewal in R6/2 mice. A, Immunohistochemical labeling of Tbr2 and melanopsin in whole-mount retinas from AAV-EGFP- or AAV-Tbr2-EGFPinjected eyes in age-matched R6/2 and control mice aged 10.5 weeks. Arrowheads indicate ipRGCs with double labeling of melanopsin and Tbr2 or single labeling of Tbr2. B, Bar graph showing numbers of Tbr2(+) RGCs in 10.5-week-old mice. C, Quantification of the Tbr2 fluorescence intensity per RGC or ipRGC in 10.5-week-old mice. D, Quantification of the melanopsin fluorescence intensity per ipRGC in 10.5-week-old mice. $\boldsymbol{E}$, Number of ipRGCs determined in each group of mice aged 10.5 weeks. (3- 4 retinal areas per mouse randomly selected for the quantification in $\boldsymbol{B}, \boldsymbol{C}, \boldsymbol{D}$, and $\boldsymbol{E}$ ( $n=3-4$ per group). Scale bar in $\boldsymbol{A}, 20 \mu \mathrm{m}$. Data are presented as the means \pm SEM. ${ }^{*} p<0.05,{ }^{* *} p<0.01,{ }^{* * *} p<0.001$, \#p $<0.05$, \#\#p $<0.01$, \#\#\# $<0.001$, two-way ANOVA. 
A

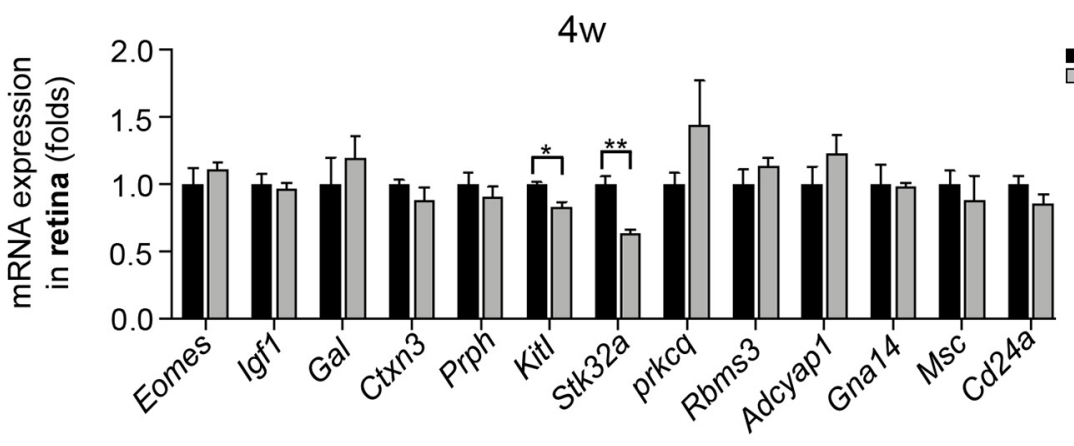

B

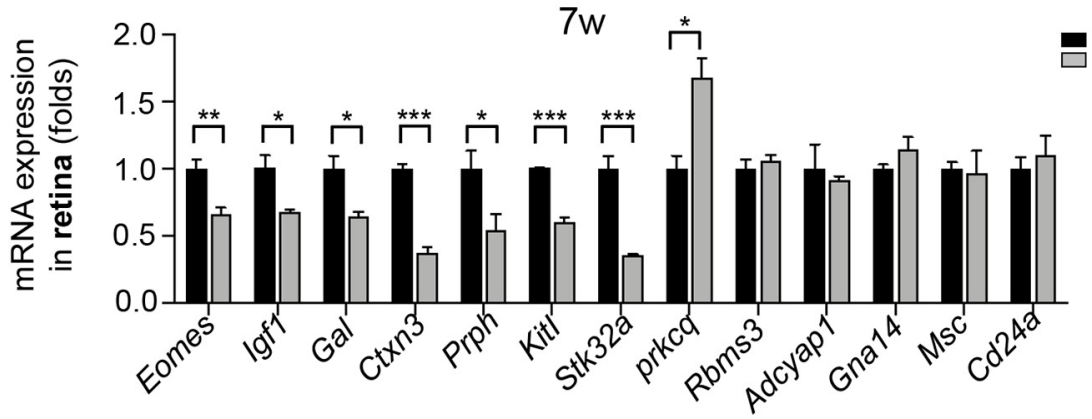

C

RNAscope ${ }^{\circledR}$ assay
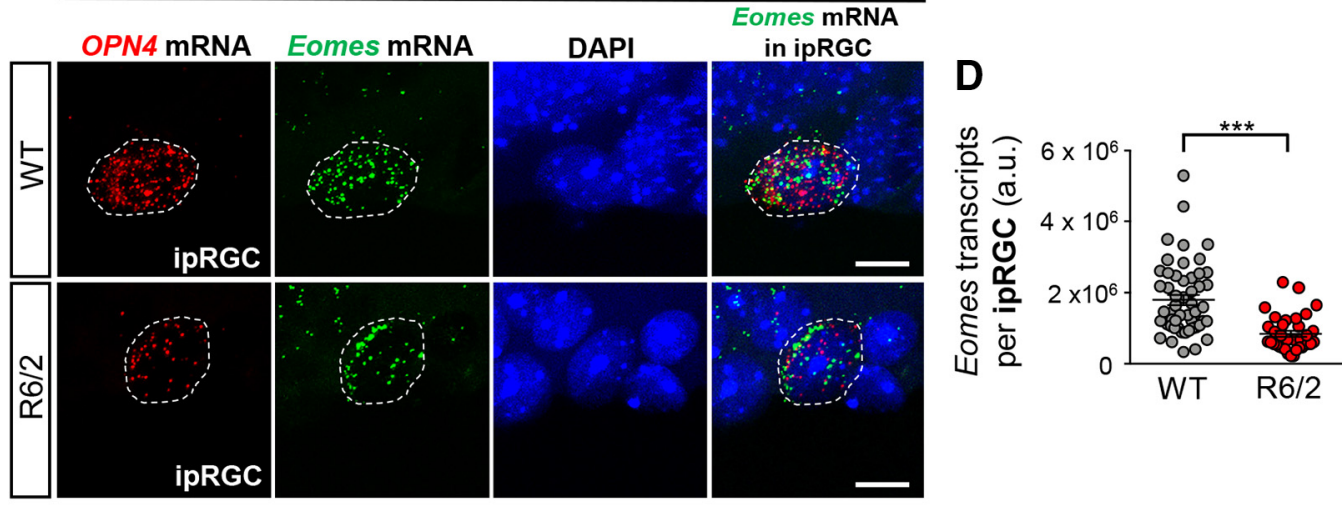

$\mathbf{E}$

$7 w$

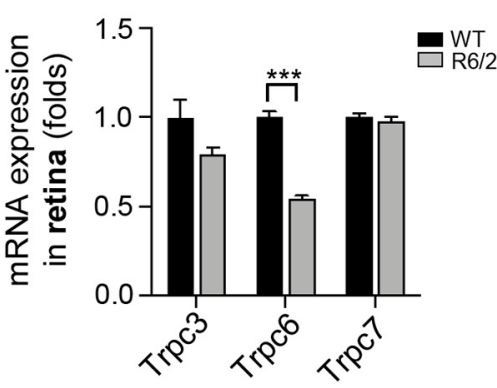

$\square \mathrm{WT}$

W6/2
F
$12 \mathrm{w}$

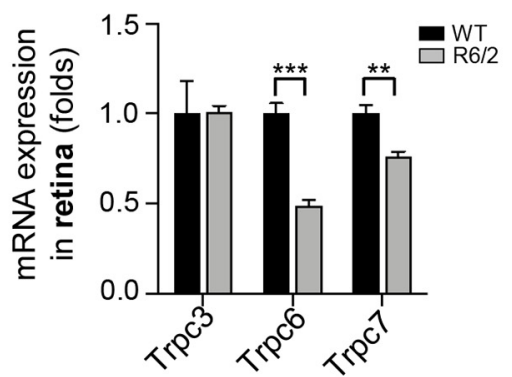

Figure 6. Altered gene expression profiles of ipRGCs in R6/2 mice. $A, B$, Transcript levels of ipRGC-enriched genes analyzed in retinal RNA extracts of R6/2 mice and control mice at the ages of 4 weeks $(\boldsymbol{A})$ and 7 weeks $(\boldsymbol{B})(n=3 \sim 4$ for each group of mice). $\boldsymbol{C}$, Representative images showing that coexpression of OPN4 and Eomes mRNA in single ipRGCs in the coronal section of the retina in $\mathrm{R} 6 / 2$ and control mice at the age of 7 weeks by in situ hybridization (RNAscope assay). $\boldsymbol{D}$, Bar graph showing Eomes mRNA expression per ipRGC, which is identified as OPN4 mRNA-clustered cells, in R6/2 and age-matched control mice. In total, $53 \mathrm{ipRGCs}$ in control mice $(n=4)$ and $35 \mathrm{ipRGCS} \mathrm{in} \mathrm{R6/2} \mathrm{mice}(n=4)$ were measured in this assay. The cells with $>10$ mRNA particles were considered to be successfully labeled. $\boldsymbol{E}, \boldsymbol{F}$, Transcript levels of Trpc3, Trpc6, and Trpc7 analyzed in retinal RNA extracts of R6/2 mice and control mice at the ages of 7 weeks $(\boldsymbol{E})$ and 12 weeks $(\boldsymbol{F})(n=3-6$ for the indicated mice). Scale bar in C, $10 \mu \mathrm{m}$. Data are shown as the means \pm SEM. ${ }^{*} p<0.05,{ }^{* *} p<0.01,{ }^{* * *} p<0.001$, unpaired $t$ test.

anopsin expression in $\mathrm{R} 6 / 2$ retina, but not in WT retina (two-way ANOVA, $F_{(1,46)}=8.14, p=0.006$, post hoc AAV-Tbr2- and AAVEGFP-infected WT mice, $t_{(46)}=1.41, p=0.16$, post hoc AAVTbr2- and AAV-EGFP-infected R6/2 mice, $t_{(46)}=2.82, p=$ 0.007; Fig. 5D). Tbr2 overexpression did not affect the number of ipRGCs in R6/2 mice (two-way ANOVA, $F_{(1,44)}=1.835, p=$
0.18, post hoc AAV-Tbr2- and AAV-EGFP-infected R6/2 mice, $t_{(44)}=0.83, p=0.40$; Fig. $5 E$ ), suggesting that supplementation of Tbr2 alone is not sufficient to restore the survival of ipRGCs. Surprisingly, enhanced expression of Tbr2 in WT retina resulted in an increase in the number of ipRGCs (two-way ANOVA, post $h o c$ AAV-Tbr2- and AAV-EGFP-infected WT mice, $t_{(44)}=2.41$, 

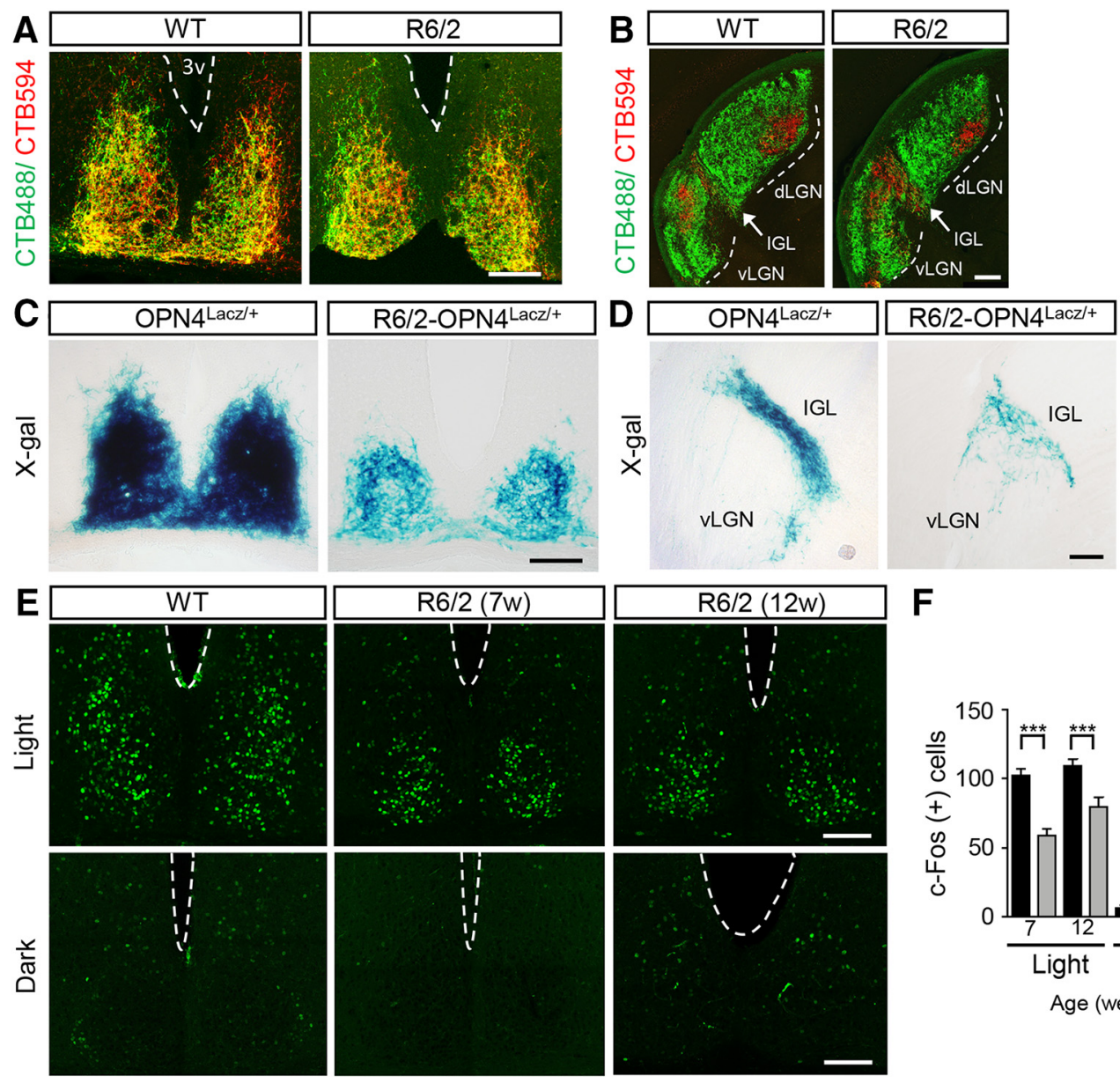

$\mathbf{F}$
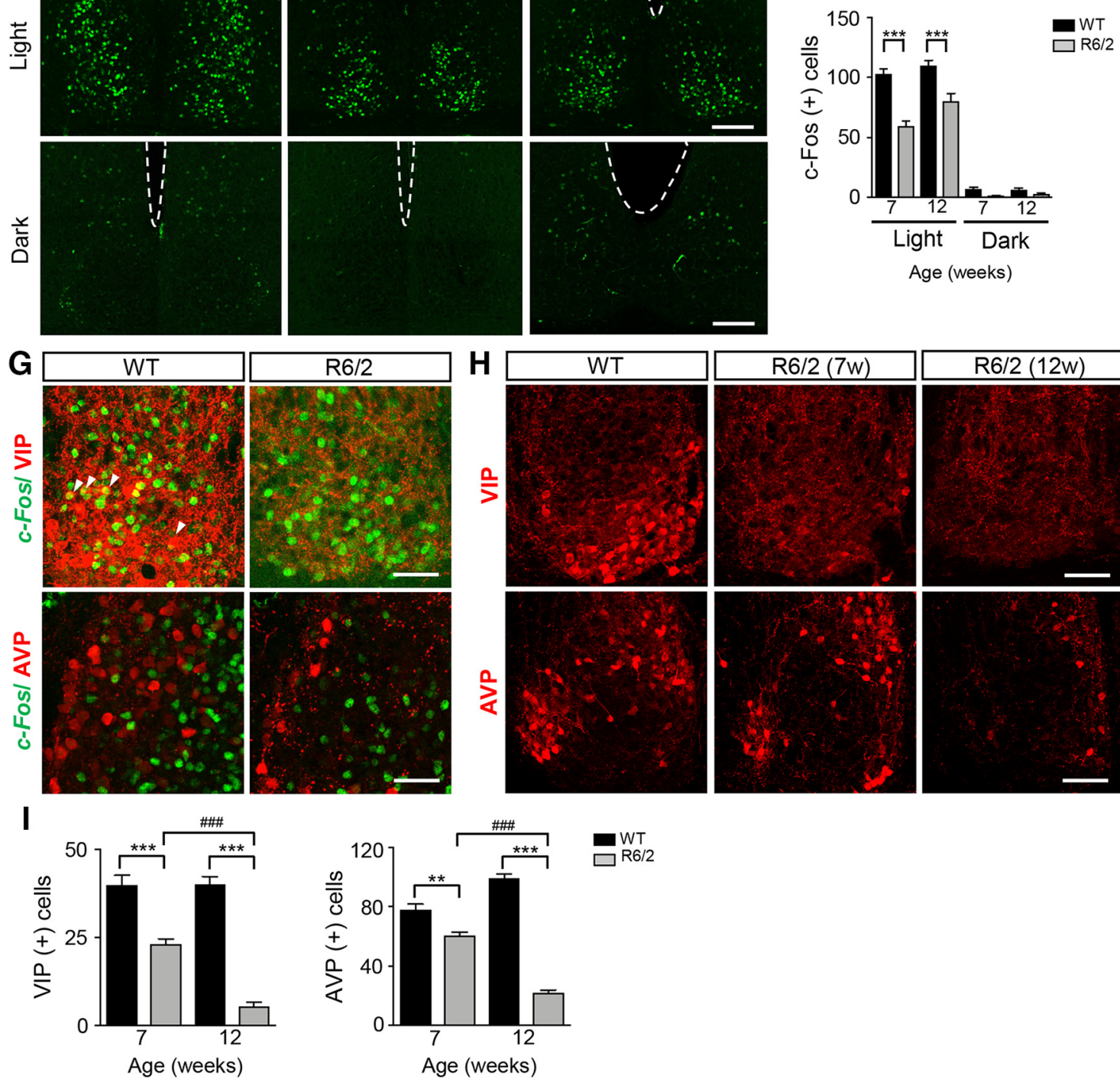

Figure 7. Synergistic decrease of retinal input and VIP- and AVP-positive neurons in the R6/2SCN. $A, B$, Confocal images showing no differences in the double CTb-labeled RGC innervation of the SCN $(\boldsymbol{A})$ or IGL and LGN $(\boldsymbol{B})$ between R6/2 mice and control mice at the age of 12 weeks $(n=5-6$ for the indicated mice). $\boldsymbol{C}$, $\boldsymbol{D}$, Representative images showing the X-gal-labeled M1-ipRGC innervation in the SCN $(\boldsymbol{C})$ and IGL and ventral LGN (D) of R6/2-0PN4 ${ }^{\text {Lacz/+ }}$ or OPN4 ${ }^{\text {Lacz/+ }}$ mice at the age of 12 weeks $(n=3-4$ for the indicated mice). $\boldsymbol{E}$, Representative images of light- induced c-Fos expression in the SCN after mice ( $n=3-5$ for the indicated mice) received 15 min of light exposure (500 lux) at ZT16, detected by anti-c-Fos antibodies. The $c$-Fos expression in the SCN in the absence of light stimulation at ZT16 is shown as an experimental control ( $n=3$ for the indicated mice). $\boldsymbol{F}$, Numbers of $c$-Fos positive neurons under light (Figure legend continues.) 
$p=0.019$ ), which might be because Tbr2-expressing RGCs are the reservoir of ipRGCs (Mao et al., 2014) and therefore might contribute to the enhanced number of ipRGCs by Tbr2 overexpression (Fig. 5E). Together, the supplementation of Tbr2 in HD ipRGCs by itself is sufficient to recover the reduced melanopsin level, but not to enhance ipRGC survival.

\section{Altered gene expression profiles in ipRGCs of HD mice (R6/2)} To determine whether the downregulation of melanopsin and Tbr2 are due to global reductions in transcription levels or whether mutant HTT may specifically influence certain genes, we assessed 13 ipRGC-enriched genes in R6/2 mice at the presymptomatic stage using qRT-PCR (Siegert et al., 2012). We found that only KitI (unpaired $t$ test, $t_{(4)}=5.96, p=0.003$ ) and Stk32a $\left(t_{(4)}=4.49, p=0.01\right)$ were downregulated in $\mathrm{R} 6 / 2$ retinas at 4 weeks (Fig. 6A). In contrast, at the age of 7 weeks, when ipRGC numbers showed minor reductions, Eomes $\left(t_{(5)}=4.22, p=\right.$ $0.008)$, Igfl $\left(t_{(5)}=3.88, p=0.01\right)$, Gal $\left(t_{(5)}=3.79, p=0.01\right)$, $\operatorname{Ctxn3}\left(t_{(5)}=11.29, p<0.0001\right), \operatorname{Prph}\left(t_{(5)}=2.57, p=0.04\right)$, KitI $\left(t_{(5)}=10.08, p=0.0001\right)$, and Stk32a $\left(t_{(5)}=8.19, p=0.0004\right)$ were downregulated, whereas $\operatorname{Prkcq}\left(t_{(5)}=3.74, p=0.01\right)$ was upregulated in R6/2 retinas compared with control mice (Fig. 6B). There were no changes in Rbms3, Adcyap1, Gna14, Msc, and $C d 24 a$ levels in retinas between R6/2 and control mice (Fig. $6 A, B)$. We further confirmed whether this reduction of Tbr2 is predominant in ipRGCs at the presymptomatic stage in R6/2 mice by using the RNAscope assay (Wang et al., 2012). OPN4 and Eomes RNA probes were used to label the melanopsin and Tbr2 mRNAs in the retina of 7 -week-old R6/2 mice (Fig. 6C). The Eomes transcript level in HD ipRGCs, marked by the expression of OPN4, was significantly lower than that in WT ipRGCs at the presymptomatic stage (unpaired $t$ test, $t_{(86)}=5.17, p<0.0001$; Fig. $6 D$ ), confirming that the reduced level of Eomes in HD retina was caused by the reduction in Eomes transcripts, but not the death of ipRGCs. Consistent with our qRT-PCR data showing that the OPN4 transcript level in R6/2 mice was lower than that in WT mice, the RNAscope assay also revealed that the levels of OPN4 transcript in R6/2 ipRGCs were $80 \%$ lower than that of control ipRGCs. The amounts of OPN4 transcripts in WT and R6/2 mice were $1.6 \times 10^{5} \pm 1.7 \times 10^{4}$ and $3.3 \times 10^{4} \pm 2.6 \times 10^{3}$ (a.u.), respectively (unpaired $t$ test, $t_{(86)}=6.011, p<0.0001$ ). We also evaluated whether the transient receptor potential channels, the downstream targets of melanopsin signaling (Panda et al., 2005; Perez-Leighton et al., 2011; Xue et al., 2011), were altered by the decrease of melanopsin. We found that a reduction of Trpc6 occurred at the presymptomatic stage (unpaired $t$ test, $t_{(5)}$ $=13.61, p<0.0001$ ), followed by the downregulation of Trpc7 at the symptomatic stage (unpaired $t$ test, $t_{(9)}=4.52, p=0.001$; Fig. $6 E, F)$. However, there was no significant change in Trpc3 transcript levels throughout disease progression. Together, our results indicate that mutant HTT may globally alter the gene

\section{$\leftarrow$}

(Figure legend continued.) stimulation or no light conditions in the indicated mice of different ages are presented. G, Confocal images showing that light-induced (-Fos was partially detected in VIP-immunoreactive neurons (arrowheads) in control mice (12 weeks), which was not seen in AVP-immunoreactive neurons. Note that c-Fos/VIP-immunoreactive neurons were reduced in $\mathrm{R} 6 / 2$ mice relative to control mice at the age of 12 weeks ( $n=5$ for each group). $\boldsymbol{H}$, Changes in VIP( + ) neurons and $\mathrm{AVP}(+)$ neurons in $\mathrm{SCN}$ from mice at 7 and 12 weeks of ages. $I$, Numbers of $\operatorname{VIP}(+)$ and $\operatorname{AVP}(+)$ neurons in the indicated mice during disease progression ( $n=3-6$ for each group). Scale bars: $\boldsymbol{A}-\boldsymbol{E}, 100 \mu \mathrm{m} ; \boldsymbol{G}, 25 \mu \mathrm{m} ; \boldsymbol{H}, 50 \mu \mathrm{m} .{ }^{* *} p<0.01,{ }^{* * *} p<$ 0.001 , \#\#p $<0.001$, two-way ANOVA. expression profiles in ipRGCs, which may affect the physiological function of ipRGCs before the onset of motor symptoms.

\section{Inferior photic input from ipRGCs to SCN in HD mice (R6/2)}

Because we observed a reduced number of M1 ipRGCs in the retina during the progression of disease, we next evaluated the innervation of RGCs or M1-ipRGCs in SCN or the LGN via intravitreally delivered cholera toxin B subunit (CTb) 488 and 594 in $\mathrm{R} 6 / 2$ mice or by X-gal staining in $\mathrm{R} 6 / 2-\mathrm{OPN} 4{ }^{\mathrm{Lacz} /+}$ mice. The CTb-labeled fibers in SCN or LGN in R6/2 mice were comparable to those in control mice (Fig. $7 A, B$ ); however, the X-gal-labeled fibers, as the M1 innervation, in SCN and the IGL in R6/2 mice were decreased relative to control mice (Fig. $7 C, D$ ). This suggests that M1 ipRGC is vulnerable rather than other RGCs in R6/2 mice. It has been shown that M1 ipRGCs are the major SCNprojecting ipRGC subtype; however, $\sim 20 \%$ of SCN-projecting ipRGCs are non-M1 ipRGCs (Baver et al., 2008). Therefore, in $\mathrm{R} 6 / 2$ mice, our data suggested that the reduction of retinal input to $\mathrm{SCN}$ is a primarily due to the M1 subtype.

To evaluate whether the photic input from ipRGCs to SCN is altered in R6/2 mice, we examined the levels of light-induced c-Fos in SCN of mice at different ages. c-Fos is one of the most common light-regulated genes, which indicates the level of photic input to SCN and other subcortical vision regions, such as the IGL and vLGN. (Castel et al., 1997; Prichard et al., 2002). Although 15 min of 500 lux light exposure successfully induced expression of nuclear c-Fos in SCN in R6/2 mice (Fig. 7E), there was a significant reduction in c-Fos-positive cells at the presymptomatic stage as well as at the symptomatic stage (two-way ANOVA, $F_{(1,80)}=1.772, p=0.1870$, post hoc with 7-week-old R6/2 vs control mice, $t_{(80)}=5.441, p<0.0001,12$-week-old R6/2 vs control mice, $t_{(80)}=4.381, p<0.0001$; Fig. $\left.7 F\right)$, confirming inferior photic input to SCN. We also found that light-induced c-Fos emerged from several VIP neurons in WT SCN, but not in R6/2 SCN. c-Fos did not arise from AVP neurons in response to light stimulation in both WT and R6/2 mice (Fig. 7G). This suggested that, not only the light-induced c-fos, but also the level of neuropeptides might be altered by M1 degeneration.

A recent study reported that the axon terminals of ipRGCs are directly connected to AVP neurons and VIP neurons in SCN (Fernandez et al., 2016), whereas the neuropeptide level in SCN is reduced in constant darkness compared with an LD cycle (Dardente et al., 2004). This indicates that the decrease in photic input may alter neuropeptide levels in the SCN. We therefore evaluated the longitudinal change of AVP- or VIP-immunoreactive neurons in R6/2 mice (Fig. 7H). As expected, the numbers of VIPand AVP-immunoreactive neurons were both decreased in R6/2 SCN at presymptomatic and symptomatic stages (two-way ANOVA with $\operatorname{VIP}(+)$ neurons, $F_{(1,84)}=19.22, p<0.0001$, post hoc with 7-week-old R6/2 vs control mice, $t_{(84)}=5.88, p<$ 0.0001; 12-week-old R6/2 vs control mice, $t_{(84)}=12.08, p<$ 0.0001 ; with $\mathrm{AVP}(+)$ neurons, $F_{(1,56)}=120.2, p<0.0001$, post hoc with 7-week-old R6/2 vs control mice, $t_{(56)}=4.028, p=$ 0.001 ; 12 -week-old R6/2 vs control mice, $t_{(56)}=22.88, p<$ 0.0001; Fig. 7I). Because no change in the neuron numbers in SCN have been reported in R6/2 mice (Fahrenkrug et al., 2007), our results suggested a progressive downregulation of VIP and AVP during disease progression. Together, we revealed that reduced numbers and innervations of M1 ipRGCs contribute to reduced photic input ( $c$-fos) and the downregulation of VIP and AVP in R6/2 SCN. 
A

A

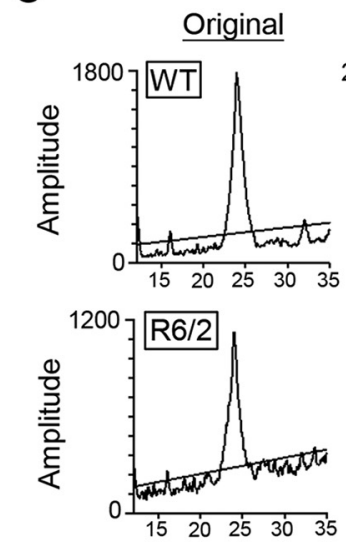

$\mathbf{F}$
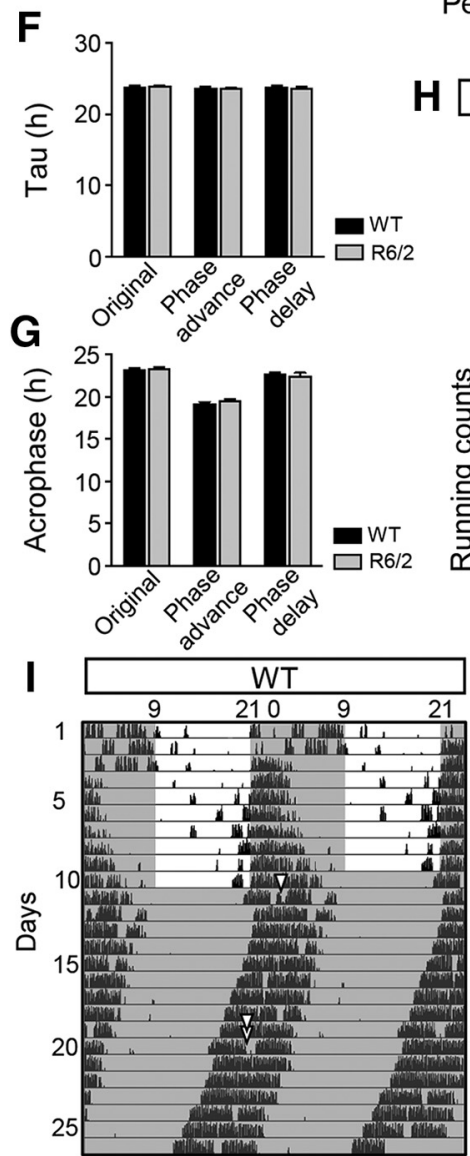
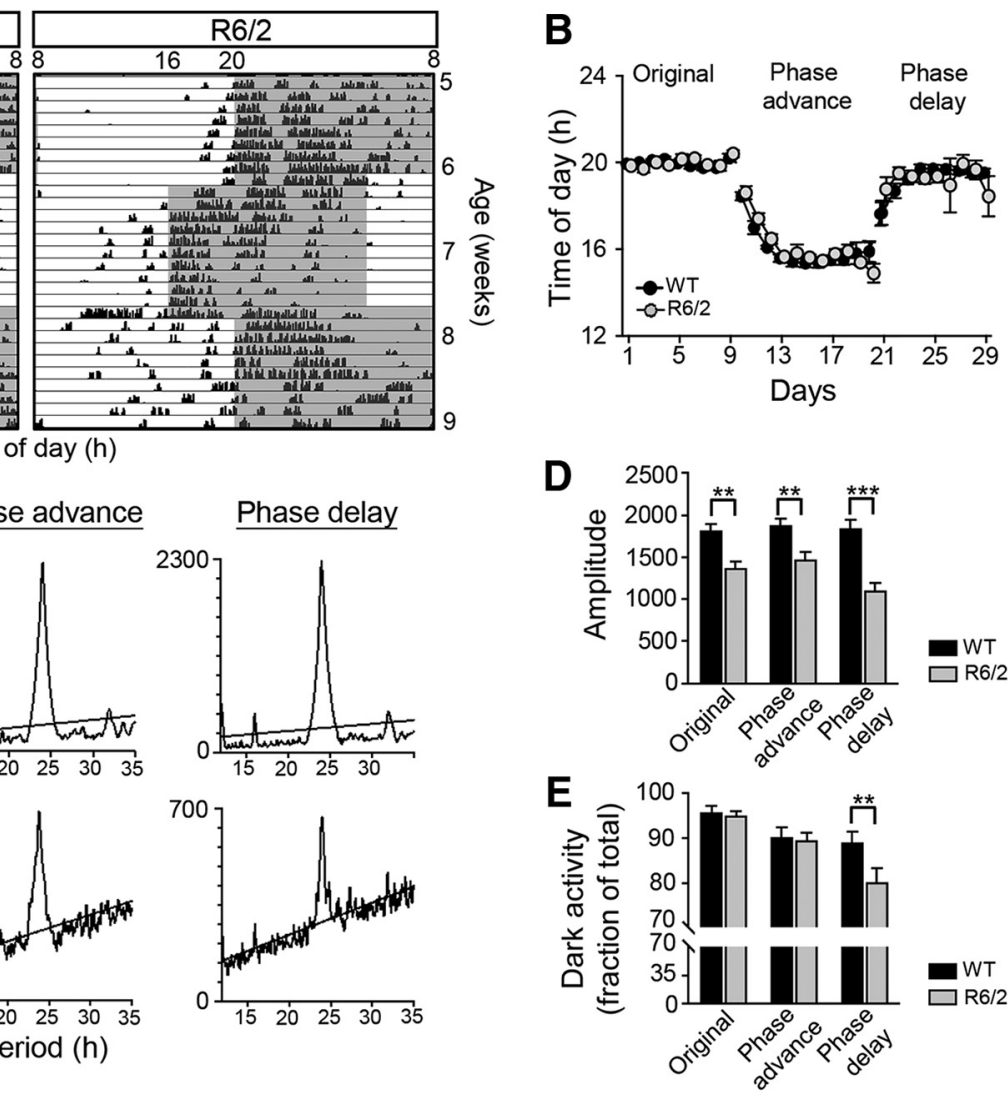
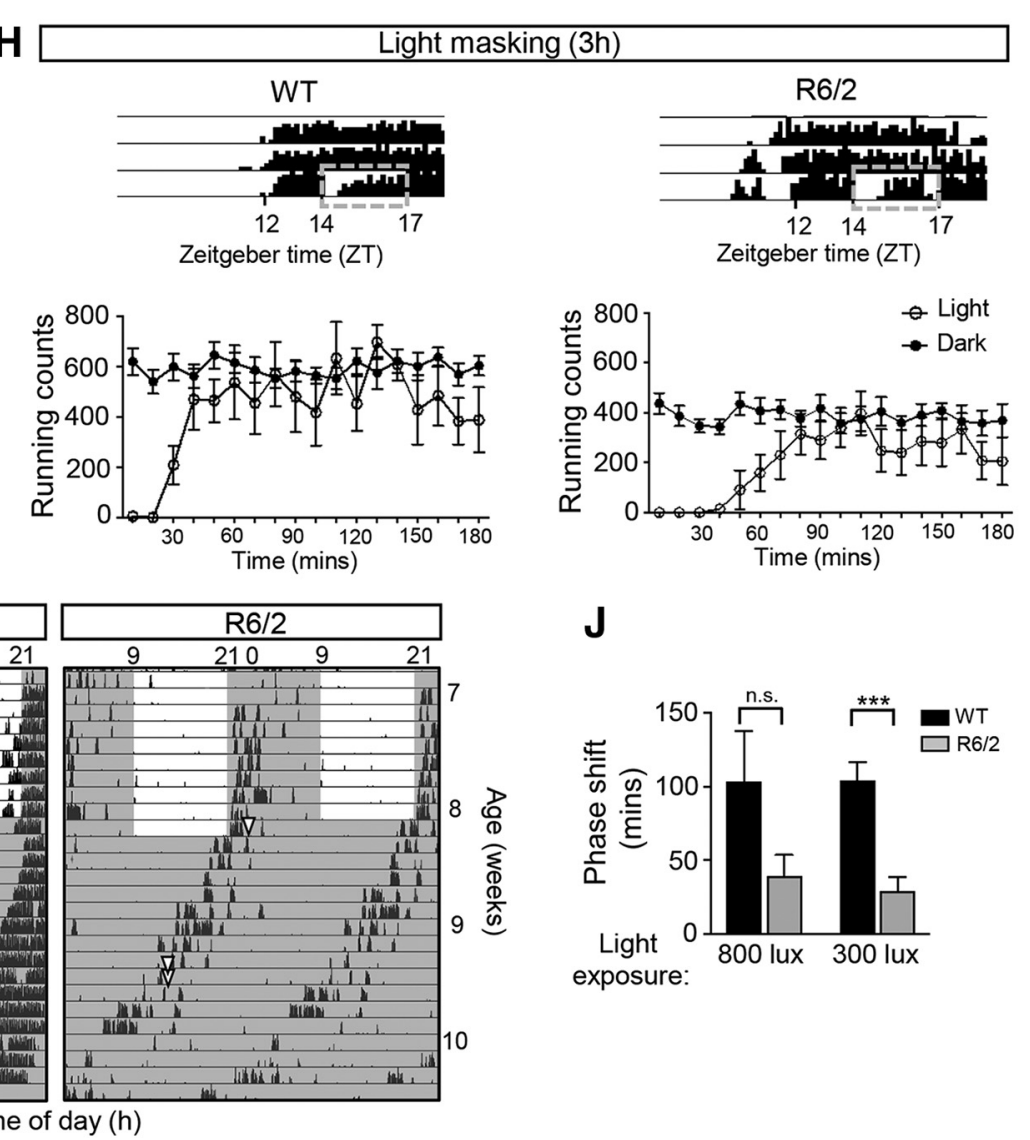

$\mathbf{J}$

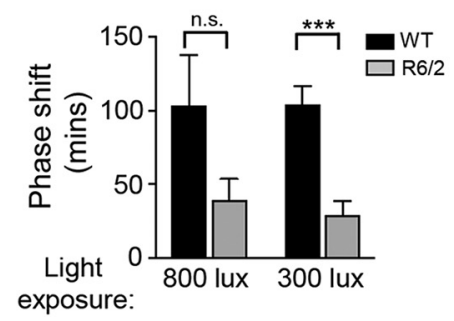

Figure 8. R6/2 mice display increased daily activity at the presymptomatic stage. $\boldsymbol{A}$, Representative single-plotted actogram wheel-running activities of R6/2 mice ( $n=17)$ and littermate wild-type controls ( $n=14$ ) are shown. Mice were entrained to $12 \mathrm{~h} / 12 \mathrm{~h} \mathrm{LD}$ cycles for $9 \mathrm{~d}$ (original), followed by a $4 \mathrm{~h}$ phase advance of LD cycles for $11 \mathrm{~d}$ (phase advance), and were then returned to the original LD cycle for $9 \mathrm{~d}$ (phase delay) from 5-9 weeks of age. The white background represents the lightness; the gray background indicates the darkness. $\boldsymbol{B}$, Times of activity onset in these mice were recorded from day 1 to day 29; the end of phase advance and phase delay were observed at day 14 and day 23, respectively. $\mathbf{C}$, Peaks in the corresponding (Figure legend continues.) 


\section{Progressive impairment of circadian photoentrainment in HD mice (R6/2)}

Here, we assumed that the reduced photic input to SCN might affect the circadian regulation in R6/2 mice, specifically before the onset of motor impairment. Previous reports have shown that R6/2 mice displayed circadian impairments after the onset of motor symptoms, although this phenotype remains unclear before motor impairment (Morton et al., 2005; Kudo et al., 2011; Wood et al., 2013). To evaluate whether the circadian photoentrainment is altered by the early disruption of ipRGC properties, $4 \mathrm{~h}$ phase advance and delay and $3 \mathrm{~h}$ light masking in a dark period were assessed by wheel-running activity with mice from the ages of 5 to 9 weeks (Fig. 8A) and 7 weeks (Fig. $8 H$ ), respectively. We found that R6/2 mice were normally entrained to a $4 \mathrm{~h}$ phase advance and delay (Fig. $8 B$ ), although the amplitude of the circadian rhythms, as assessed by $\chi^{2}$ periodogram, were significantly decreased in R6/2 mice in all phases of the experiment (two-way ANOVA with genotype, $F_{(1,28)}=29.46, p<0.0001$, post hoc the difference in original, $t_{(84)}=3.54, p=0.006$; in phase advance, $t_{(84)}=3.26, p=0.001$; in phase delay, $t_{(84)}=5.49, p<$ 0.0001 ; Fig. $8 C, D)$. Interestingly, R6/2 mice showed relatively higher activity in the light period during a $24 \mathrm{~h}$ period at the age of 8-9 weeks (two-way ANOVA with different phases, $F_{(2,58)}=$ 21.87, $p<0.0001$, post hoc the difference in phase delay, $t_{(87)}=$ 3.06, $p=0.002$; Fig. $8 E$ ) before significant motor dysfunction occurred (Fig. 1H). However, the length of the circadian period (tau) (Fig. $8 F$ ) and the onset of activity rhythm (acrophase) (Fig. $8 G$ ) remained normal in R6/2 mice. For 3 h light masking, although OPN4 knock-out mice displayed an impaired masking response to light in wheel-running activities (Mrosovsky and Hattar, 2003), our results showed no significant changes of acute light-suppressed wheel-running activities in R6/2 mice compared with control mice at the presymptomatic stage (activities in light relative to in dark in control vs R6/2 mice at first h: $46 \pm$ $7.1 \%$ vs $9.8 \pm 5.4 \%$; at second h: $87.5 \pm 19.0 \%$ vs $74.5 \pm 15.3 \%$; at third h: $83.1 \pm 95 \%$ vs $65.5 \pm 6.3 \%$, two-way ANOVA with genotype, $F_{(1,10)}=2.29$, $p=0.16$; Fig. $8 H$ ). To further evaluate the impact of light on the circadian clock in R6/2 mice, the lightinduced phase shifts of free running activities in mice were examined (Fig. 8I). Our results showed that R6/2 mice did not differ from control mice according to an 800 lux light stimulation (unpaired $t$ test, $\left.t_{(14)}=1.934, p=0.07\right)$. Conversely, under 300 lux light exposure, R6/2 mice displayed a phase delay of $28 \pm 9 \mathrm{~min}$,

$\leftarrow$

(Figure legend continued.) $\quad \chi^{2}$ periodogram for each mouse show a dominant period during $12 \mathrm{~h} / 12 \mathrm{~h} \mathrm{LD}$ cycles before, during, and after $4 \mathrm{~h}$ phase advances. Peaks above the diagonal line (representing the $99.9 \%$ confidence level) between 12 and $35 \mathrm{~h}$ reflected significant circadian periods. $D$, Amplitude of circadian rhythms was lower in each $L D$ cycle in $R 6 / 2$ mice relative to control mice. Bars show the amplitudes at the dominant period, obtained from $\chi^{2}$ periodogram analysis. $\boldsymbol{E}$, Activities in the dark relative to the daily activity of each mouse were averaged before, during, and after $4 \mathrm{~h}$ phase advances of the LD cycle. $\boldsymbol{F}$, Circadian periods (tau) that mice displayed measured in the indicated LD cycles. $\boldsymbol{G}$, Onset of wheel-running activities, defined as the acrophase, was recorded in the indicated LD cycles. $H$, Mice at the age of 7 weeks maintained in $12 \mathrm{~h} / 12 \mathrm{~h} \mathrm{LD}$ cycles were exposed to a single $3 \mathrm{~h}, 800$ lux light pulse at ZT14. The light period is highlighted by the gray dotted box on single-plotted wheel-running activities. The running activities in the light period relative to those in the dark period for each animal were plotted every 10 min from ZT14 to ZT17 ( $n=6$ for each group). I, Representative double-plotted actograms showing that wheel-running activities of $\mathrm{R} 6 / 2(n=9)$ and control mice $(n=7)$ held in a LD cycle until day 10 followed by constant darkness from 7 to 10.5 weeks of age. Mice were exposed to a 15 min 800 lux light pulse (arrow) at CT16 on day 11, followed by a 30 min 300 lux light pulse (double arrows) at CT16 on day 20.J, Changes in the circadian phase due to different intensities of light for the indicated mice. Values are presented as the means \pm SEM. ${ }^{* *} p<$ $0.01,{ }^{* * *} p<0.001$, two-way ANOVA and unpaired $t$ test. which was significantly shorter than the phase shift in WT mice by $103 \pm 12 \mathrm{~min}$ (unpaired $t$ test, $t_{(14)}=4.876, p=0.0002$; Fig. $8 J$ ), suggesting the direct impact of ipRGC loss on the circadian response to light. Together, our results showed that the reduction of ipRGC input to SCN could potentially dampen the oscillation amplitude similar to constant dark treatment, even before the onset of motor dysfunction in R6/2 mice, although the remaining ipRGCs were sufficient for entrainment of the circadian clock to a $24 \mathrm{~h}$ period.

\section{Impaired PLR in HD mice (R6/2)}

To test whether the impaired ipRGC function is specific to circadian photoentrainment, we next tested whether PLR, which is controlled by a different subset of ipRGCs from circadian photoentrainment (Chen et al., 2011), was affected by HD in R6/2 mice. Previous studies suggest that pupil constriction to light at high irradiance is preferentially mediated by melanopsindependent signaling (Lucas et al., 2003), whereas pupil constriction in response to lower-intensity light is primarily mediated by rod and cone photoreceptors (Güler et al., 2008). To distinguish the contributions of photoreceptor and melanopsin signaling to pupil constriction during disease progression, we evaluated PLRs to high-intensity (500 lux) and low-intensity (5 lux) light in mice. In contrast to photic input to the SCN, R6/2 mice showed PLR deficits under 500 lux light stimulation only after entering the symptomatic stage (two-way ANOVA, $F_{(2,65)}=1.153, p=$ 0.3222 , post hoc at 10.5 weeks, $t_{(65)}=2.20, p=0.030$; Fig. $\left.9 A, C\right)$. However, the 5 lux light-induced pupil light reflex was not disrupted in R6/2 mice throughout disease progression (two-way ANOVA, $F_{(2,54)}=0.2825, p=0.76$; Fig. $\left.9 A, B\right)$, suggesting that the classic photoreceptor rod and cone input to ipRGCs for PLR remains largely normal. Furthermore, CTb-labeled RGC fibers in OPN showed no difference in $\mathrm{R} 6 / 2$ mice relative to control mice, whereas X-gal-labeled M1 ipRGC fibers in OPN was significantly reduced in R6/2 mice (Fig. 9D). Together with Figure 3E, the weakened synaptic connections in PLR circuit, both findings were supportive of PLR impairment in R6/2 mice at the symptomatic stage. M1 degeneration also attenuated PLR. Our behavior tests confirmed that mutant HTT may influence distinctive types of ipRGCs and their functions at different ages.

\section{Discussion}

In this study, we reported that ipRGC degeneration was associated with the accumulation of mutant HTT in these cells in mouse models of HD. Previously, the loss of ipRGC was associated with amyloid- $\beta(\mathrm{A} \beta)$ deposition as well as circadian dysregulation in $\mathrm{AD}$ patients (La Morgia et al., 2016). The $\alpha$-synuclein deposition in the inner retina of patients with Parkinson's disease has also been reported (Bodis-Wollner et al., 2014). These studies and our study support that retina and ipRGC with progressive changes are related to circadian impairment in neurodegenerative diseases (La Morgia et al., 2017). Interestingly, ipRGCs are more resilient than other types of RGCs in several disease models (such as chronic ocular hypertension (Li et al., 2006), optic nerve crash (Li et al., 2008), and Leber hereditary optic neuropathy with inherited mitochondrial dysfunction (La Morgia et al., 2010). It is possible that ipRGCs are prone to the protein-aggregation-induced neurodegeneration, but less to other types of physical injuries or inherited mitochondrial impairment. 


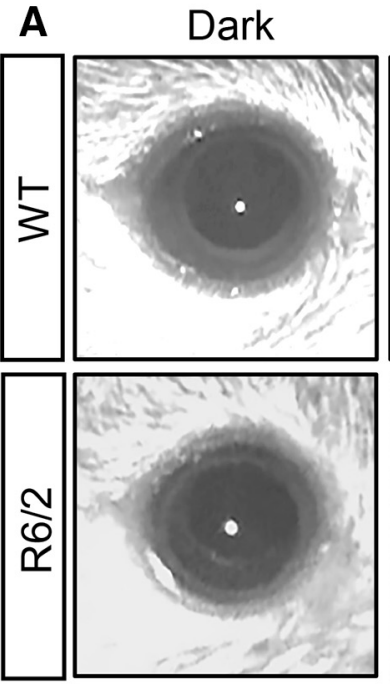

B

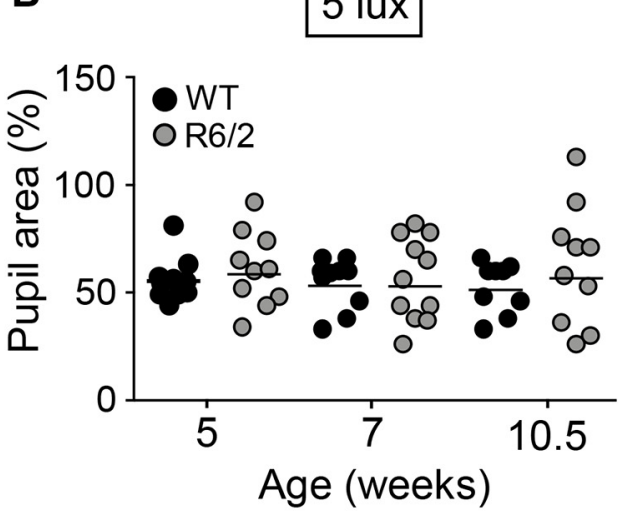

D

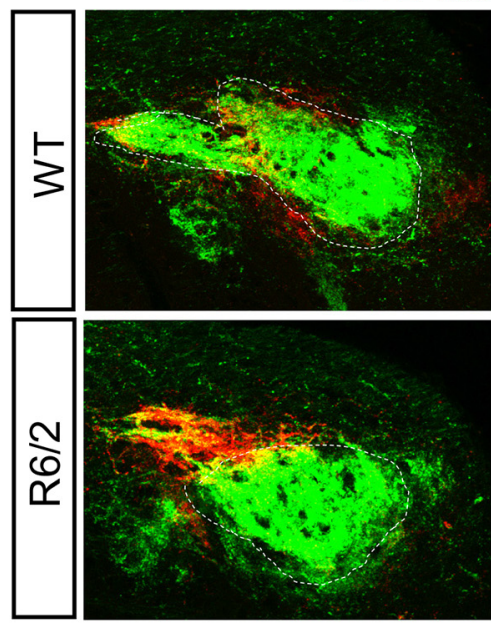

\section{CTB594}

$5 \operatorname{lux}$
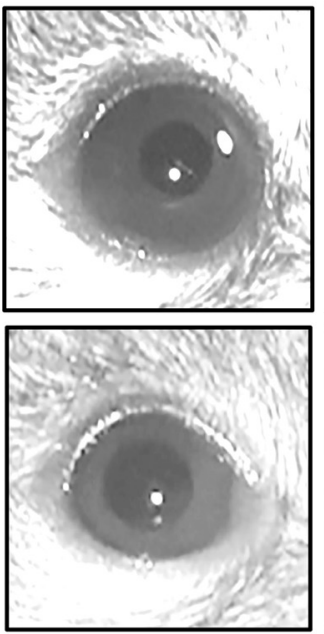
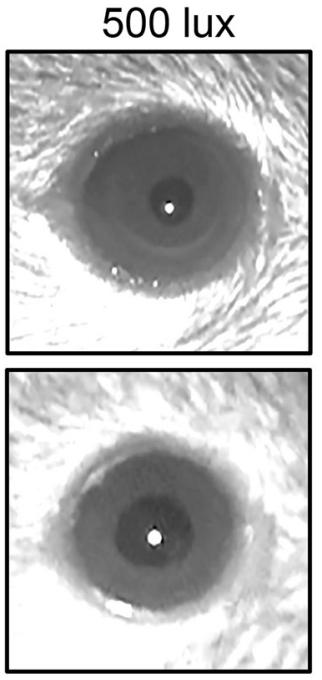

C

$500 \operatorname{lux}$
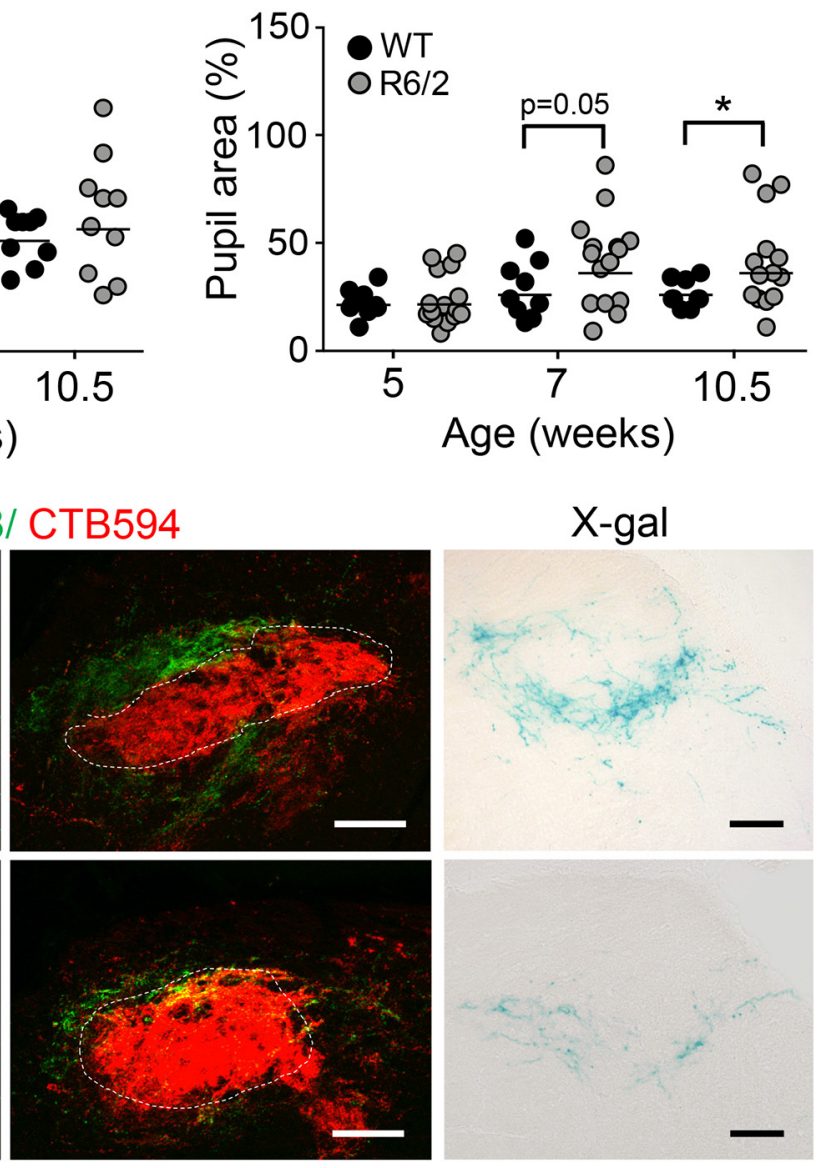

Figure 9. Changes in pupil constriction in response to light in R6/2 mice. A, Pupil constriction induced by 30 s of light analyzed in R6/2 mice $(n=15)$ and control mice $(n=9)$ at the ages of 5 , 7, and 10.5 weeks. Representative images show the pupillary constriction of 10.5 -week-old mice in response to 5 and 500 lux light, respectively. B, C, Maximal response of pupil constriction extracted from 11 to $23 \mathrm{~s}$ during the $30 \mathrm{~s}$ constriction in response to light presented as the relative change in the pupil area. Note that $100 \%$ of the relative pupil area is defined as a pupil without constriction. Light-induced pupil constriction at 5 lux $(\boldsymbol{B})$ and 500 lux $(\boldsymbol{C})$ in the indicated mice is shown. $\boldsymbol{D}$, Confocal images showing that double $(T b-l a b e l e d ~ R G C$ innervation in the bilateral 0 PN of the indicated mice at 12 weeks of age ( $n=5-6$ for each group) and the X-gal-labeled M1-ipRGC innervation in the OPN of R6/2-0PN4 ${ }^{\text {Lacz } /+}$ or OPN4 ${ }^{\text {Laz } /+}$ mice at 12 weeks of age ( $n=3-4$ for each group). Data are presented as the means \pm SEM. ${ }^{*} p<0.05$, two-way ANOVA.

Possible mechanism underlying the suppression of ipRGC by mutant HTT

Here, we suspected that mutant HTT affects the melanopsin expression and the survival of ipRGCs though multiple pathways.
We found that ipRGCs in R6/2 mice started to decrease before the onset of motor impairment, whereas ipRGCs in N171-82Q mice (16 weeks) were decreased after the onset of motor impairment (14 weeks) (Boudreau et al., 2009). Because mutant HTT is ex- 
pressed in both neurons and glia in R6/2 mice and that N171-82Q mice express mutant HTT only in neurons, this finding indicated that mutant HTT in retinal non-neuronal cells might accelerate the physiopathological changes of ipRGCs. Although mutant HTT disruption of transcriptional regulation through direct binding to transcription factors (Stott et al., 1995) or obstruction of epigenetic modifications ( $\mathrm{Ng}$ et al., 2013) have been reported, we showed that proximal promoter activity of melanopsin was not interfered with by transiently overexpressed 109Q-expanded HTT exon 1 in vitro. A previous study suggested that melanopsin mRNA is regulated by the activation of the dopamine $D_{2}$ receptor in ipRGCs through direct contact with amacrine cells (Sakamoto et al., 2005). The altered dendritic structures and decreased dopamine production in amacrine cells disrupt synaptic connections to ipRGCs, which leads to reduced melanopsin expression (Li et al., 2012). Here, R6/2 mice showed reduced synaptic connections from ipRGCs to amacrine cells, which might affect the expression of melanopsin in R6/2 mice. We infer that the cell non-autonomous pathway might be involved in the process of ipRGC degeneration.

Next, we observed that several ipRGC-enriched genes such as Tbr2 were altered before the apoptosis of ipRGCs. In addition, we demonstrated that exogenous expression of Tbr2 in in the retina of HD mice (R6/2) was able to increase the level of melanopsin in ipRGCs, but was unable to rescue the survival of ipRGCs (Fig. 5). Previous studies have demonstrated that genetic deletion of Tbr2 in mature ipRGCs led to the loss of ipRGCs ( $90 \%)$, suggesting the role of Tbr2 in the formation/survival of ipRGCs (Mao et al., 2014). The requirement of Tbr2 in melanopsin expression and circuit formation for the pupil light reflex during developmental stage have also been proven (Mao et al., 2014; Sweeney et al., 2014; Seabrook et al., 2017). Given that replenishment of Tbr2 in ipRGCs is not sufficient to increase the survival of ipRGCs of R6/2 mice (Fig. 5E), it is very likely that other genes that are affected by mutant HTT in ipRGCs might also contribute to the Tbr2-mediated ipRGC survival. As detailed above, expression of mutant HTT affects the expression of many ipRGC-enriched genes. Among them, KitI controls the differentiation of retinal progenitor cells in the developing retina (Koso et al., 2007). Igf1 and Gal serve as growth factors/neuromodulators in CNS and show neuroprotective effects in the pathological brain (Bassil et al., 2014; Lang et al., 2015). Prph is important for the formation of outer segment disc of photoreceptors (Molday and Goldberg, 2017). Prkcq is an important energy mediator for regulating insulin signaling in the CNS (Benoit et al., 2009). It remains to be determined whether these genes in part control the survival of ipRGCs during HD progression. Together, our findings suggest that mutant HTT in ipRGC changes the expression of Tbr2 and other genes that might together regulate the survival and/or functions of ipRGC. The suppression of ipRGC by mutant HTT might be synergistically controlled by cell non-autonomous and autonomous pathways.

\section{From inferior photic input in SCN to aberrant circadian behavior}

We observed that, before the onset of motor dysfunction, R6/2 mice already showed dampened rhythms in locomotor activities and reduced phase shift under low-light conditions. The observations concerning increased diurnal activities in R6/2 mice is in agreement with previous studies of R6/2 mice (Morton et al., 2005) and BACHD mice (Kudo et al., 2011; Loh et al., 2013). Removal of Tbr2 in mature ipRGC leads to a severe loss of ipRGC and higher daily activities during the $12 \mathrm{~h} \mathrm{LD}$ cycles or the $4 \mathrm{~h} \mathrm{LD}$ ultradian cycles (Panda et al., 2002; Mao et al., 2014). Interestingly, the survival of 100-200 ipRGCs in ipRGC-disrupted mice (Opn $4^{\mathrm{aDTA} /+}$ mice) is sufficient to drive circadian photoentrainment (Güler et al., 2008). This may explain why R6/2 mice have normal masking to light, because these mice at the symptomatic stage still have half of the M1 ipRGCs. Therefore, a loss of ipRGCs could dampen the daily rhythm and reduce the efficiency of lightinduced phase shift but might not completely block the ability to produce circadian photoentrainment in R6/2 mice.

Our data also showed that the light-induced c-fos was compromised and the expressions of VIP and AVP were reduced in R6/2 SCN, suggesting a reduced M1 innervation. We speculated that this inferior photic input to SCN may play an important role in the abnormal diurnal activities in R6/2 mice. Melanopsindependent photic input exclusively altered the light-regulated Fos transcripts in SCN (Tsai et al., 2009; Jagannath et al., 2013), confirming that c-fos activation insensitive to light is due to a reduction of melanopsin. A progressive reduction of VIP and AVP in R6/2 SCN further suggested reduced environmental light transmission to SCN neurons because it has been shown that light could enhance VIP expression in SCN (Dardente et al., 2004); therefore, a reduction of neuropeptides expression could be the result of reduced M1 innervation. Earlier studies suggest that lacking VIP causes attenuated circadian amplitude of rhythms, increased daily activity (Aton et al., 2005), and reduced SCN c-fos levels to light (Dragich et al., 2010), so we inferred that M1 degeneration contributes to the dampened rhythms through VIP downregulation in R6/2 mice. Although early studies reported the importance of vasopressin (AVP) in circadian output and the onset of circadian photoentrainment (Jin et al., 1999; Kalsbeek et al., 2010; Mieda et al., 2015), there is no supporting evidence that the disrupted AVP in SCN might lead to abnormal diurnal rhythm. Together, we speculate that inferior M1 innervation attenuates the light-induced c-fos and VIP in SCN that initiates and prolongs the circadian abnormalities in R6/2 mice. However, we could not exclude the possibility that the downregulated VIP and AVP might contribute to direct interactions with mutant HTT.

\section{Defective circuits related to the modulation of PLR}

We identified that the reduced M1 projection to OPN and impaired PLR circuit traced by PRV152 were correlated to the attenuated pupil response to light in R6/2 mice. The impaired circuit labeled by PRV152 might indicate the decreased synaptic connection or altered efficacy in axonal transport. According to previous studies, the impaired connectivity of neuronal networks is the common feature of HD. The dysfunction of corticostriatal circuits serve as the major contributor to the motor dysregulation in HD (Hamilton et al., 2003; Cepeda et al., 2007) and the impaired corticostriatal electrophysiological connectivity has been reported in R6/2 (Cepeda et al., 2003) and zQ175 mice (Heikkinen et al., 2012). Furthermore, the aberrant LTP in hippocampal CA1 and CA3 synapses links the altered synaptic plasticity to cognitive behavioral changes in mouse models of HD (R6/2 and YAC) (Hodgson et al., 1999; Murphy et al., 2000). Therefore, the impaired synaptic connectivity in HD is not only restricted in corticostriatal and hippocampal regions, but also in ipRGCrelated circuit. This also explains the occurrence of nonmotor symptoms simultaneously correlated with corticostriatal impairment.

The transmission of pseudorabies virus within neurons and their axons is basically through vesicle transport (Taylor and Enquist, 2015) and the efficient axonal transport of PRV rely on the protein translation for cytoskeletal remodeling and axonal traf- 
ficking (Koyuncu et al., 2013). Expression of mutant HTT is known to cause abnormal axonal transport of mitochondria and BDNF-containing vesicles in cortical and striatal neurons (Gauthier et al., 2004; Reddy and Shirendeb, 2012). It remains unclear whether mutant HTT jeopardizes the axonal transport in other types of neurons, such as those neurons involved in the PLR circuit. Our results suggest that impaired circuit followed by M1 degeneration is likely to contribute to the abnormal PLR in HD. Further analyses to verify the role of abnormal circuit in nonimage-forming behaviors is needed in the future.

\section{Impact of ipRGC degeneration on the health of HD patients} ipRGC degeneration may also contribute to sleep modulation and/or cognition in HD. Sleep abnormalities have been reported in HD patients and in HD mouse models, including increased nighttime activity and daytime tiredness (Aziz et al., 2010; Fisher et al., 2013). Previous studies have indicated that melanopsin is essential for modulating sleep homeostasis through regulating the ventrolateral preoptic neurons as well as in SCN neurons (Lupi et al., 2008; Tsai et al., 2009). Furthermore, melanopsin and ipRGC are required for sensing environmental light correctly to modulate cognition, mood, and other light-modulated brain functions (LeGates et al., 2012). Although the dysfunction of melanopsin and the ipRGC system have not yet been confirmed in HD patients, our study suggests a regulatory role of melanopsin and ipRGC in circadian rhythms and PLR, perhaps even in sleep and cognition in HD.

\section{References}

Aton SJ, Colwell CS, Harmar AJ, Waschek J, Herzog ED (2005) Vasoactive intestinal polypeptide mediates circadian rhythmicity and synchrony in mammalian clock neurons. Nat Neurosci 8:476-483. CrossRef Medline

Aziz NA, Anguelova GV, Marinus J, Lammers GJ, Roos RA (2010) Sleep and circadian rhythm alterations correlate with depression and cognitive impairment in Huntington's disease. Parkinsonism and related disorders 16:345-350. CrossRef Medline

Bassil F, Fernagut PO, Bezard E, Meissner WG (2014) Insulin, IGF-1 and GLP-1 signaling in neurodegenerative disorders: targets for disease modification? Prog Neurobiol 118:1-18. CrossRef Medline

Baver SB, Pickard GE, Sollars PJ, Pickard GE (2008) Two types of melanopsin retinal ganglion cell differentially innervate the hypothalamic suprachiasmatic nucleus and the olivary pretectal nucleus. Eur J Neurosci 27: 1763-1770. CrossRef Medline

Benoit SC, Kemp CJ, Elias CF, Abplanalp W, Herman JP, Migrenne S, Lefevre AL, Cruciani-Guglielmacci C, Magnan C, Yu F, Niswender K, Irani BG, Holland WL, Clegg DJ (2009) Palmitic acid mediates hypothalamic insulin resistance by altering PKC-theta subcellular localization in rodents. J Clin Invest 119:2577-2589. CrossRef Medline

Berson DM, Dunn FA, Takao M (2002) Phototransduction by retinal ganglion cells that set the circadian clock. Science 295:1070-1073. CrossRef Medline

Berson DM, Castrucci AM, Provencio I (2010) Morphology and mosaics of melanopsin-expressing retinal ganglion cell types in mice. J Comp Neurol 518:2405-2422. CrossRef Medline

Bodis-Wollner I, Kozlowski PB, Glazman S, Miri S (2014) alpha-synuclein in the inner retina in Parkinson disease. Ann Neurol 75:964-966. CrossRef Medline

Boudreau RL, McBride JL, Martins I, Shen S, Xing Y, Carter BJ, Davidson BL (2009) Nonallele-specific silencing of mutant and wild-type huntingtin demonstrates therapeutic efficacy in Huntington's disease mice. Mol Ther 17:1053-1063. CrossRef Medline

Card JP, Enquist LW (2014) Transneuronal circuit analysis with pseudorabies viruses. Curr Protoc Neurosci 68:1.5.1-1.5.39. CrossRef Medline

Carter RJ, Lione LA, Humby T, Mangiarini L, Mahal A, Bates GP, Dunnett SB, Morton AJ (1999) Characterization of progressive motor deficits in mice transgenic for the human Huntington's disease mutation. J Neurosci 19:3248-3257. CrossRef Medline

Castel M, Belenky M, Cohen S, Wagner S, Schwartz WJ (1997) Light- induced c-fos expression in the mouse suprachiasmatic nucleus: immunoelectron microscopy reveals co-localization in multiple cell types. Eur J Neurosci 9:1950-1960. CrossRef Medline

Cepeda C, Hurst RS, Calvert CR, Hernández-Echeagaray E, Nguyen OK, Jocoy E, Christian LJ, Ariano MA, Levine MS (2003) Transient and progressive electrophysiological alterations in the corticostriatal pathway in a mouse model of Huntington's disease. J Neurosci 23:961-969. CrossRef Medline

Cepeda C, Wu N, André VM, Cummings DM, Levine MS (2007) The corticostriatal pathway in Huntington's disease. Prog Neurobiol 81:253-271. CrossRef Medline

Chen SK, Badea TC, Hattar S (2011) Photoentrainment and pupillary light reflex are mediated by distinct populations of ipRGCs. Nature 476:92-95. CrossRef Medline

Chiang MC, Lee YC, Huang CL, Chern Y (2005) cAMP-response elementbinding protein contributes to suppression of the $\mathrm{A} 2 \mathrm{~A}$ adenosine receptor promoter by mutant huntingtin with expanded polyglutamine residues. J Biol Chem 280:14331-14340. CrossRef Medline

Dardente H, Menet JS, Challet E, Tournier BB, Pévet P, Masson-Pévet M (2004) Daily and circadian expression of neuropeptides in the suprachiasmatic nuclei of nocturnal and diurnal rodents. Brain Res Mol Brain Res 124:143-151. CrossRef Medline

Dragich JM, Loh DH, Wang LM, Vosko AM, Kudo T, Nakamura TJ, Odom IH, Tateyama S, Hagopian A, Waschek JA, Colwell CS (2010) The role of the neuropeptides PACAP and VIP in the photic regulation of gene expression in the suprachiasmatic nucleus. Eur J Neurosci 31:864-875. CrossRef Medline

Ecker JL, Dumitrescu ON, Wong KY, Alam NM, Chen SK, LeGates T, Renna JM, Prusky GT, Berson DM, Hattar S (2010) Melanopsin-expressing retinal ganglion-cell photoreceptors: cellular diversity and role in pattern vision. Neuron 67:49-60. CrossRef Medline

Fahrenkrug J, Popovic N, Georg B, Brundin P, Hannibal J (2007) Decreased VIP and VPAC2 receptor expression in the biological clock of the R6/2 Huntington's disease mouse. J Mol Neurosci 31:139-148. Medline

Fernandez DC, Chang YT, Hattar S, Chen SK (2016) Architecture of retinal projections to the central circadian pacemaker. Proc Natl Acad Sci U S A 113:6047-6052. CrossRef Medline

Fisher SP, Black SW, Schwartz MD, Wilk AJ, Chen TM, Lincoln WU, Liu HW, Kilduff TS, Morairty SR (2013) Longitudinal analysis of the electroencephalogram and sleep phenotype in the R6/2 mouse model of Huntington's disease. Brain 136:2159-2172. CrossRef Medline

Gauthier LR, Charrin BC, Borrell-Pagès M, Dompierre JP, Rangone H, Cordelières FP, De Mey J, MacDonald ME, Lessmann V, Humbert S, Saudou F (2004) Huntingtin controls neurotrophic support and survival of neurons by enhancing BDNF vesicular transport along microtubules. Cell 118:127-138. CrossRef Medline

Güler AD, Ecker JL, Lall GS, Haq S, Altimus CM, Liao HW, Barnard AR, Cahill H, Badea TC, Zhao H, Hankins MW, Berson DM, Lucas RJ, Yau KW, Hattar S (2008) Melanopsin cells are the principal conduits for rod-cone input to non-image-forming vision. Nature 453:102-105. CrossRef Medline

Hamada T, Antle MC, Silver R (2004) Temporal and spatial expression patterns of canonical clock genes and clock-controlled genes in the suprachiasmatic nucleus. Eur J Neurosci 19:1741-1748. CrossRef Medline

Hamilton JM, Haaland KY, Adair JC, Brandt J (2003) Ideomotor limb apraxia in Huntington's disease: implications for corticostriate involvement. Neuropsychologia 41:614-621. CrossRef Medline

Hattar S, Liao HW, Takao M, Berson DM, Yau KW (2002) Melanopsincontaining retinal ganglion cells: architecture, projections, and intrinsic photosensitivity. Science 295:1065-1070. CrossRef Medline

Hattar S, Kumar M, Park A, Tong P, Tung J, Yau KW, Berson DM (2006) Central projections of melanopsin-expressing retinal ganglion cells in the mouse. J Comp Neurol 497:326-349. CrossRef Medline

Heikkinen T, Lehtimäki K, Vartiainen N, Puoliväli J, Hendricks SJ, Glaser JR, Bradaia A, Wadel K, Touller C, Kontkanen O, Yrjänheikki JM, Buisson B, Howland D, Beaumont V, Munoz-Sanjuan I, Park LC (2012) Characterization of neurophysiological and behavioral changes, MRI brain volumetry and 1H MRS in zQ175 knock-in mouse model of Huntington's disease. PLoS One 7:e50717. CrossRef Medline

Helmlinger D, Yvert G, Picaud S, Merienne K, Sahel J, Mandel JL, Devys D (2002) Progressive retinal degeneration and dysfunction in R6 Huntington's disease mice. Hum Mol Genet 11:3351-3359. CrossRef Medline 
Hodgson JG, Agopyan N, Gutekunst CA, Leavitt BR, LePiane F, Singaraja R, Smith DJ, Bissada N, McCutcheon K, Nasir J, Jamot L, Li XJ, Stevens ME, Rosemond E, Roder JC, Phillips AG, Rubin EM, Hersch SM, Hayden MR (1999) A YAC mouse model for Huntington's disease with full-length mutant huntingtin, cytoplasmic toxicity, and selective striatal neurodegeneration. Neuron 23:181-192. CrossRef Medline

Hu C, Hill DD, Wong KY (2013) Intrinsic physiological properties of the five types of mouse ganglion-cell photoreceptors. J Neurophysiol 109: 1876-1889. CrossRef Medline

Jagannath A, Butler R, Godinho SIH, Couch Y, Brown LA, Vasudevan SR, Flanagan KC, Anthony D, Churchill GC, Wood MJA, Steiner G, Ebeling M, Hossbach M, Wettstein JG, Duffield GE, Gatti S, Hankins MW, Foster RG, Peirson SN (2013) The CRTC1-SIK1 pathway regulates entrainment of the circadian clock. Cell 154:1100-1111. CrossRef Medline

Jin X, Shearman LP, Weaver DR, Zylka MJ, de Vries GJ, Reppert SM (1999) A molecular mechanism regulating rhythmic output from the suprachiasmatic circadian clock. Cell 96:57-68. CrossRef Medline

Kalsbeek A, Fliers E, Hofman MA, Swaab DF, Buijs RM (2010) Vasopressin and the output of the hypothalamic biological clock. J Neuroendocrinol 22:362-372. CrossRef Medline

Koso H, Satoh S, Watanabe S (2007) c-kit marks late retinal progenitor cells and regulates their differentiation in developing mouse retina. Developmental biology 301:141-154. CrossRef Medline

Koyuncu OO, Perlman DH, Enquist LW (2013) Efficient retrograde transport of pseudorabies virus within neurons requires local protein synthesis in axons. Cell Host Microbe 13:54-66. CrossRef Medline

Kudo T, Schroeder A, Loh DH, Kuljis D, Jordan MC, Roos KP, Colwell CS (2011) Dysfunctions in circadian behavior and physiology in mouse models of Huntington's disease. Exp Neurol 228:80-90. CrossRef Medline

La Morgia C, Ross-Cisneros FN, Sadun AA, Hannibal J, Munarini A, Mantovani V, Barboni P, Cantalupo G, Tozer KR, Sancisi E, Salomao SR, Moraes MN, Moraes-Filho MN, Heegaard S, Milea D, Kjer P, Montagna P, Carelli V (2010) Melanopsin retinal ganglion cells are resistant to neurodegeneration in mitochondrial optic neuropathies. Brain 133: 2426-2438. CrossRef Medline

La Morgia C, Ross-Cisneros FN, Koronyo Y, Hannibal J, Gallassi R, Cantalupo G, Sambati L, Pan BX, Tozer KR, Barboni P, Provini F, Avanzini P, Carbonelli M, Pelosi A, Chui H, Liguori R, Baruzzi A, Koronyo-Hamaoui M, Sadun AA, Carelli V (2016) Melanopsin retinal ganglion cell loss in alzheimer disease. Ann Neurol 79:90-109. CrossRef Medline

La Morgia C, Ross-Cisneros FN, Sadun AA, Carelli V (2017) Retinal ganglion cells and circadian rhythms in Alzheimer's disease, Parkinson's disease, and beyond. Front Neurol 8:162. CrossRef Medline

Lang R, Gundlach AL, Holmes FE, Hobson SA, Wynick D, Hökfelt T, Kofler B (2015) Physiology, signaling, and pharmacology of galanin peptides and receptors: three decades of emerging diversity. Pharmacol Rev 67: 118-175. Medline

LeGates TA, Altimus CM, Wang H, Lee HK, Yang S, Zhao H, Kirkwood A, Weber ET, Hattar S (2012) Aberrant light directly impairs mood and learning through melanopsin-expressing neurons. Nature 491:594-598. CrossRef Medline

Lei B, Zhang K, Yue Y, Ghosh A, Duan D (2009) Adeno-associated virus serotype-9 efficiently transduces the retinal outer plexiform layer. Mol Vis 15:1374-1382. Medline

Lei B, Zhang K, Yue Y, Ghosh A, Duan D (2010) Adeno-associated virus serotype-9 mediated retinal outer plexiform layer transduction is mainly through the photoreceptors. Adv Exp Med Biol 664:671-678. CrossRef Medline

Li RS, Chen BY, Tay DK, Chan HH, Pu ML, So KF (2006) Melanopsinexpressing retinal ganglion cells are more injury-resistant in a chronic ocular hypertension model. Invest Ophthalmol Vis Sci 47:2951-2958. CrossRef Medline

Li SY, Yau SY, Chen BY, Tay DK, Lee VW, Pu ML, Chan HH, So KF (2008) Enhanced survival of melanopsin-expressing retinal ganglion cells after injury is associated with the PI3 K/Akt pathway. Cell Mol Neurobiol 28:1095-1107. CrossRef Medline

Li Y, Li C, Chen Z, He J, Tao Z, Yin ZQ (2012) A microRNA, mir133b, suppresses melanopsin expression mediated by failure dopaminergic amacrine cells in RCS rats. Cell Signal 24:685-698. CrossRef Medline

Lin CH, Tallaksen-Greene S, Chien WM, Cearley JA, Jackson WS, Crouse AB, Ren S, Li XJ, Albin RL, Detloff PJ (2001) Neurological abnormalities in a knock-in mouse model of Huntington's disease. Hum Mol Genet 10:137144. CrossRef Medline

Lin YS, Cheng TH, Chang CP, Chen HM, Chern Y (2013) Enhancement of brain-type creatine kinase activity ameliorates neuronal deficits in Huntington's disease. Biochim Biophys Acta 1832:742-753. CrossRef Medline

Loh DH, Kudo T, Truong D, Wu Y, Colwell CS (2013) The Q175 mouse model of Huntington's disease shows gene dosage- and age-related decline in circadian rhythms of activity and sleep. PLoS One 8:e69993. CrossRef Medline

Lucas RJ, Hattar S, Takao M, Berson DM, Foster RG, Yau KW (2003) Diminished pupillary light reflex at high irradiances in melanopsinknockout mice. Science 299:245-247. CrossRef Medline

Lupi D, Oster H, Thompson S, Foster RG (2008) The acute light-induction of sleep is mediated by OPN4-based photoreception. Nat Neurosci 11: 1068-1073. CrossRef Medline

Mao CA, Li H, Zhang Z, Kiyama T, Panda S, Hattar S, Ribelayga CP, Mills SL, Wang SW (2014) T-box transcription regulator Tbr2 is essential for the formation and maintenance of Opn4/melanopsin-expressing intrinsically photosensitive retinal ganglion cells. J Neurosci 34:13083-13095. CrossRef Medline

Mieda M, Ono D, Hasegawa E, Okamoto H, Honma K, Honma S, Sakurai T (2015) Cellular clocks in AVP neurons of the SCN are critical for interneuronal coupling regulating circadian behavior rhythm. Neuron 85: 1103-1116. CrossRef Medline

Molday RS, Goldberg AFX (2017) Peripherin diverts ciliary ectosome release to photoreceptor disc morphogenesis. J Cell BIol 216:1227-1229. CrossRef Medline

Mombaerts P, Wang F, Dulac C, Chao SK, Nemes A, Mendelsohn M, Edmondson J, Axel R (1996) Visualizing an olfactory sensory map. Cell 87:675-686. CrossRef Medline

Morton AJ (2013) Circadian and sleep disorder in Huntington's disease. Exp Neurol 243:34-44. CrossRef Medline

Morton AJ, Wood NI, Hastings MH, Hurelbrink C, Barker RA, Maywood ES (2005) Disintegration of the sleep-wake cycle and circadian timing in Huntington's disease. J Neurosci 25:157-163. CrossRef Medline

Mrosovsky N, Hattar S (2003) Impaired masking responses to light in melanopsin-knockout mice. Chronobiol Int 20:989-999. CrossRef Medline

Murphy KP, Carter RJ, Lione LA, Mangiarini L, Mahal A, Bates GP, Dunnett SB, Morton AJ (2000) Abnormal synaptic plasticity and impaired spatial cognition in mice transgenic for exon 1 of the human Huntington's disease mutation. J Neurosci 20:5115-5123. CrossRef Medline

Ng CW, Yildirim F, Yap YS, Dalin S, Matthews BJ, Velez PJ, Labadorf A, Housman DE, Fraenkel E (2013) Extensive changes in DNA methylation are associated with expression of mutant huntingtin. Proc Natl Acad Sci U S A 110:2354-2359. CrossRef Medline

Ouk K, Hughes S, Pothecary CA, Peirson SN, Morton AJ (2016) Attenuated pupillary light responses and downregulation of opsin expression parallel decline in circadian disruption in two different mouse models of Huntington's disease. Hum Mol Genet 25:ddw359. CrossRef Medline

Pallier PN, Maywood ES, Zheng Z, Chesham JE, Inyushkin AN, Dyball R, Hastings MH, Morton AJ (2007) Pharmacological imposition of sleep slows cognitive decline and reverses dysregulation of circadian gene expression in a transgenic mouse model of Huntington's disease. J Neurosci 27:7869-7878. CrossRef Medline

Panda S, Sato TK, Castrucci AM, Rollag MD, DeGrip WJ, Hogenesch JB, Provencio I, Kay SA (2002) Melanopsin (Opn4) requirement for normal light-induced circadian phase shifting. Science 298:2213-2216. CrossRef Medline

Panda S, Nayak SK, Campo B, Walker JR, Hogenesch JB, Jegla T (2005) Illumination of the melanopsin signaling pathway. Science 307:600-604. CrossRef Medline

Perez-Leighton CE, Schmidt TM, Abramowitz J, Birnbaumer L, Kofuji P (2011) Intrinsic phototransduction persists in melanopsin-expressing ganglion cells lacking diacylglycerol-sensitive TRPC subunits. Eur J Neurosci 33:856-867. CrossRef Medline

Prichard JR, Stoffel RT, Quimby DL, Obermeyer WH, Benca RM, Behan M (2002) Fos immunoreactivity in rat subcortical visual shell in response to illuminance changes. Neuroscience 114:781-793. CrossRef Medline

Reddy PH, Shirendeb UP (2012) Mutant huntingtin, abnormal mitochondrial dynamics, defective axonal transport of mitochondria, and selective 
synaptic degeneration in Huntington's disease. Biochim Biophys Acta 1822:101-110. CrossRef Medline

Rodriguez AR, de Sevilla Müller LP, Brecha NC (2014) The RNA binding protein RBPMS is a selective marker of ganglion cells in the mammalian retina. J Comp Neurol 522:1411-1443. CrossRef Medline

Sakamoto K, Liu C, Kasamatsu M, Pozdeyev NV, Iuvone PM, Tosini G (2005) Dopamine regulates melanopsin mRNA expression in intrinsically photosensitive retinal ganglion cells. Eur J Neurosci 22:3129-3136. CrossRef Medline

Schilling G, Becher MW, Sharp AH, Jinnah HA, Duan K, Kotzuk JA, Slunt HH, Ratovitski T, Cooper JK, Jenkins NA, Copeland NG, Price DL, Ross CA, Borchelt DR (1999) Intranuclear inclusions and neuritic aggregates in transgenic mice expressing a mutant $\mathrm{N}$-terminal fragment of huntingtin. Hum Mol Genet 8:397-407. CrossRef Medline

Schmidt TM, Alam NM, Chen S, Kofuji P, Li W, Prusky GT, Hattar S (2014) A role for melanopsin in alpha retinal ganglion cells and contrast detection. Neuron 82:781-788. CrossRef Medline

Seabrook TA, Dhande OS, Ishiko N, Wooley VP, Nguyen PL, Huberman AD (2017) Strict independence of parallel and poly-synaptic axon-target matching during visual reflex circuit assembly. Cell Rep 21:3049-3064. CrossRef Medline

Siegert S, Cabuy E, Scherf BG, Kohler H, Panda S, Le YZ, Fehling HJ, Gaidatzis D, Stadler MB, Roska B (2012) Transcriptional code and disease map for adult retinal cell types. Nat Neurosci 15:487-495, S1-S2. CrossRef Medline

Stott K, Blackburn JM, Butler PJ, Perutz M (1995) Incorporation of glutamine repeats makes protein oligomerize: implications for neurodegen- erative diseases. Proc Natl Acad Sci U S A 92:6509-6513. CrossRef Medline

Sweeney NT, Tierney H, Feldheim DA (2014) Tbr2 is required to generate a neural circuit mediating the pupillary light reflex. J Neurosci 34:54475453. CrossRef Medline

Taylor MP, Enquist LW (2015) Axonal spread of neuroinvasive viral infections. Trends Microbiol 23:283-288. CrossRef Medline

Tsai JW, Hannibal J, Hagiwara G, Colas D, Ruppert E, Ruby NF, Heller HC, Franken P, Bourgin P (2009) Melanopsin as a sleep modulator: circadian gating of the direct effects of light on sleep and altered sleep homeostasis in Opn4(-/-) mice. PLoS Biol 7:e1000125. CrossRef Medline

Viney TJ, Balint K, Hillier D, Siegert S, Boldogkoi Z, Enquist LW, Meister M, Cepko CL, Roska B (2007) Local retinal circuits of melanopsincontaining ganglion cells identified by transsynaptic viral tracing. Curr Biol 17:981-988. CrossRef Medline

Vonsattel JP, DiFiglia M (1998) Huntington disease. J Neuropathol Exp Neurol 57:369-384. CrossRef Medline

Wang F, Flanagan J, Su N, Wang LC, Bui S, Nielson A, Wu X, Vo HT, Ma XJ, Luo Y (2012) RNAscope: a novel in situ RNA analysis platform for formalin-fixed, paraffin-embedded tissues. J Mol Diagn 14:22-29. CrossRef Medline

Wood NI, McAllister CJ, Cuesta M, Aungier J, Fraenkel E, Morton AJ (2013) Adaptation to experimental jet-lag in R6/2 mice despite circadian dysrhythmia. PLoS One 8:e55036. CrossRef Medline

Xue T, Do MT, Riccio A, Jiang Z, Hsieh J, Wang HC, Merbs SL, Welsbie DS, Yoshioka T, Weissgerber P, Stolz S, Flockerzi V, Freichel M, Simon MI, Clapham DE, Yau KW (2011) Melanopsin signalling in mammalian iris and retina. Nature 479:67-73. CrossRef Medline 